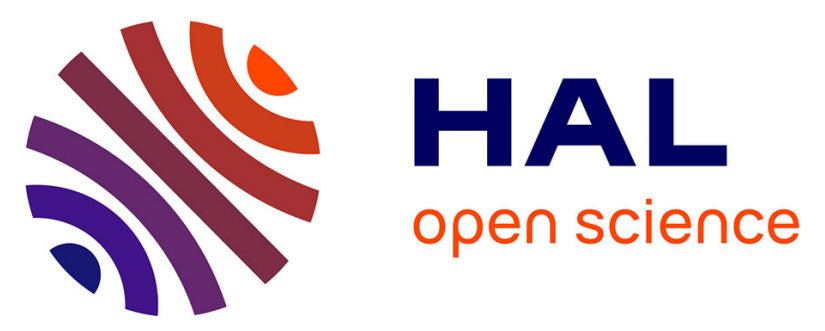

\title{
Diacylglycerol kinases activate tobacco NADPH oxidase-dependent oxidative burst in response to cryptogein
}

Jean-Luc Cacas, Patricia Gerbeau-Pissot, Jérôme Fromentin, Catherine Cantrel, Dominique Thomas, Emmanuelle Jeannette, Tetiana Kalachova, Sébastien Mongrand, Françoise Simon-Plas, Eric Ruelland

\section{To cite this version:}

Jean-Luc Cacas, Patricia Gerbeau-Pissot, Jérôme Fromentin, Catherine Cantrel, Dominique Thomas, et al.. Diacylglycerol kinases activate tobacco NADPH oxidase-dependent oxidative burst in response to cryptogein. Plant, Cell and Environment, 2016, 40 (4), pp.585-598. 10.1111/pce.12771 . hal01328631

\section{HAL Id: hal-01328631 \\ https://hal.sorbonne-universite.fr/hal-01328631}

Submitted on 8 Jun 2016

HAL is a multi-disciplinary open access archive for the deposit and dissemination of scientific research documents, whether they are published or not. The documents may come from teaching and research institutions in France or abroad, or from public or private research centers.
L'archive ouverte pluridisciplinaire HAL, est destinée au dépôt et à la diffusion de documents scientifiques de niveau recherche, publiés ou non, émanant des établissements d'enseignement et de recherche français ou étrangers, des laboratoires publics ou privés.

\section{다(1)(2)}

Distributed under a Creative Commons Attribution - ShareAlikel 4.0 International 
$4 \quad$ Running head: Control of RBOHD activity by DGK

5 Jean-Luc Cacas ${ }^{1, *}$, , Patricia Gerbeau-Pissot ${ }^{1, \S}$, Jérôme Fromentin ${ }^{1}$, Catherine Cantrel $^{2}$,

6 Dominique Thomas ${ }^{1}$, Emmanuelle Jeannette ${ }^{2}$, Tetiana Kalachova ${ }^{3,4}$, Sébastien Mongrand ${ }^{4}$,

7 Françoise Simon-Plas ${ }^{1}$, Eric Ruelland $d^{2,3,4}$

\section{Author Affiliation}

91 Agroécologie, AgroSup Dijon, CNRS, INRA, Univ. Bourgogne Franche-Comté, F-21000 
$22 \S$ These authors contributed equally to this work.

23 Corresponding author: Ruelland Eric

24 Université Paris-Est, Institute of Ecology and Environmental Sciences of Paris, CNRS/UMR

257618 61, avenue du général de Gaulle, Créteil - France

26 Telephone number: + 331451714 67. E-mail address: eric.ruelland@u-pec.fr 
28 Cryptogein is a protein secreted by the oomycete Phytophthora cryptogea that activates 29 defence mechanisms in tobacco. We show here in BY-2 tobacco suspension cells that 30 phosphatidic acid rapidly accumulates in response to cryptogein due to the coordinated onset 31 of phosphoinositide-dependent phospholipase $\mathrm{C}$ and diacylglycerol kinase activities. Both 32 enzyme specific inhibitors and silencing of the phylogenetic cluster III of the tobacco DGK 33 family were found to reduce PA production upon elicitation and to strongly decrease the RBOHD-mediated oxidative burst. This establishes that phosphatidic acid production by diacylglycerol kinases is upstream of the oxidative burst in response to cryptogein. 


\section{ABSTRACT}

Cryptogein is a $10 \mathrm{kDa}$-protein secreted by the oomycete Phytophthora cryptogea that activates defence mechanisms in tobacco plants. Among early signalling events triggered by this microbial-associated molecular pattern is a transient apoplastic oxidative burst which is dependent on the NADPH oxidase activity of the RESPIRATORY BURST OXIDASE HOMOLOG $(\mathrm{RBOH})$ isoform D. Using radioactive $\left[{ }^{33} \mathrm{P}\right]$-orthophosphate labelling of tobacco Bright Yellow-2 suspension cells, we here provide in vivo evidence for a rapid accumulation of phosphatidic acid (PA) in response to cryptogein due to the coordinated onset of phosphoinositide-dependent phospholipase $\mathrm{C}$ and diacylglycerol kinase (DGK) activities. Both enzyme specific inhibitors and silencing of the phylogenetic cluster III of the tobacco DGK family were found to reduce PA production upon elicitation and to strongly decrease the RBOHD-mediated oxidative burst. Therefore, it appears that PA originating from DGK controls NADPH-oxidase activity. Amongst cluster III DGKs, the expression of DGK5-like was up-regulated in response to cryptogein. Besides DGK5-like is likely to be the main cluster III DGK isoform silenced in one of our mutant line, making it a strong candidate for the observed response to cryptogein. The relevance of these results is discussed with regard to early signalling lipid-mediated events in plant immunity.

KEYWORDS: cryptogein, microbial-associated molecular pattern, diacylglycerol kinase; phospholipase $\mathrm{C}$, phosphatidic acid, reactive oxygen species, RBOHD, NADPH oxidase 


\section{INTRODUCTION}

Many studies have suggested that membrane lipids act as reservoirs for signalling molecules in response to developmental and environmental cues in both animal and plant cells. Indeed, under biotic or abiotic stresses, a regulated production of phospholipid-derived molecules was reported to occur, and to launch intracellular signalling cascades. Phospholipases, lipid kinases and lipid-phosphate phosphatases are considered as the main activities involved in such early signalling events (Janda et al. 2013, Sheng et al. 2015, Hawkins \& Stephens 2015, Ruelland et al. 2015).

Phosphatidic acid (PA) is the most basic phosphoglycerolipids, being composed of a diacylglycerol with a phosphoryl group esterified on the sn-3 hydroxyl of the glycerol backbone. Besides being an intermediate of phospholipid synthesis (Petroutsos et al. 2014), PA also transduces stress signals in eukaryotic cells. In serum-withdrawn fibroblast cultures for example, reverse genetic approaches have established a marked correlation between elevated endogenous PA levels and apoptosis inhibition; the latter probably being partially responsible for cancer establishment in tissues (Bruntz et al. 2014). In plants, upon pathogen attack and situations mimicking infection by the addition of elicitors, as well as under many abiotic (including drought, cold, osmotic) stresses, PA accumulation was either inferred from pharmacological strategies or directly shown by biochemical methods (Pinosa et al. 2013, Ruelland et al. 2015). In Eukaryotic cells, the synthesis of PA as a signalling molecule relies on two distinct enzymatic systems. Phospholipases D (PLD) can hydrolyse structural phospholipids within membranes, directly releasing PA (Wang et al. 2012) while, diacylglycerol kinases (DGK) can catalyse the phosphorylation of diacylglycerol (DAG) to produce PA (Arisz et al. 2009). DAG can be provided to DGK either by phosphoinositidedependent phospholipases C (PI-PLCs) that act on phosphorylated phosphoinositides or by non-specific phospholipases C (NPCs) that use structural phospholipids (Pokotylo et al. 2013, 
2014). In contrast to animal systems where both DAG and PA have been shown to act as secondary messengers, it is commonly assumed that PA plays the central role in plant cells. Indeed, no plant proteins orthologous to mammalian protein kinases $\mathrm{C}$ (which are activated through a direct interaction with DAG) have been identified from plant genomes (Dong et al. 2012), even though some proteins bearing the $\mathrm{C} 1$ domain responsible for DAG binding to PKCs have been found (Janda et al. 2013). On the other hand, up to 35 plant proteins targeted by PA have been identified on the basis of their direct interaction with the lipid (Hou et al. 2015). However, no consensus sequence to define a canonical PA binding domain was identified from these proteins.

Upon pathogen attack, two lines of defence can successively occur. The first relies on the recognition of common pathogen motifs, named microbial-associated molecular patterns (MAMPs), at the plasma membrane and this can result in basal resistance to a broad range of pathogens. The second depends on the specific perception of pathogen effectors within host cells by resistance proteins (Dangl \& Jones 2001, Jones \& Dangl 2006, Stotz et al. 2014, Bigeard et al. 2015). This latter defence response often leads to a rapid and highly localized hypersensitive cell death that prevents biotrophic pathogens from propagating (Cacas 2015). Interestingly, PA has been shown to accumulate in response to many MAMPs (xylanase, flagellin, $\mathrm{N}$-acetylchitooligosaccharide, chitosan) in several independent plant models (van der Luit et al. 2000, den Hartog 2003, Bargmann et al. 2006). PLD-, PI-PLC-, NPC- and DGK-encoding genes and/or corresponding enzymatic activities were also reported to be rapidly up-regulated in numerous studies dealing with either MAMP- or Effector-Triggered Immunity (MTI or ETI, respectively), suggesting the involvement of these lipid-modifying enzymes in early defence events (Zhang \& Xiao 2015, Ruelland et al. 2015). With the notable exception of DGK, this assumption was corroborated by several works using loss-of-function mutants. While Arabidopsis PLD $\delta$ isoform was found to be involved in MTI, multiple PLD 
isoforms were proposed to act redundantly in ETI (Pinosa et al. 2013, Johansson et al. 2014). In tomato (Solanum lycopersicum) cell suspensions, MTI involved PLDß1 (Bargmann et al. 2006) whereas full establishment of ETI required the PI-PLC-encoding gene slPLC4 (Vossen et al. 2010).

The small, basic and hydrophilic $10-\mathrm{kDa}$ protein named cryptogein is a MAMP secreted by the oomycete Phytophthora cryptogea (Ricci et al. 1989). More than two decades after its discovery, extensive investigations have provided a broad picture of cryptogein-induced physiological responses. Although this protein exhibits both cell death-promoting and systemic acquired resistance-inducing activities in tobacco (Nicotiana tabacum) plants (Keller et al. 1996, Rustérucci et al. 1999, Cacas et al. 2005), it is also able to activate many characteristic hallmarks of MTI. The interaction of cryptogein with a yet-to-be-identified protein receptor at the plasma membrane results in calcium influx (Tavernier et al. 1995, Pugin et al. 1997), potassium and chloride effluxes associated with apoplasm alkalization (Blein et al. 1991), NADPH oxidase-dependent oxidative burst (Simon-Plas et al. 2002), modification of plasma membrane order (Gerbeau-Pissot et al. 2014), activation of a MAPK cascade (Dahan et al. 2009) and clathrin-dependent endocytosis (Leborgne-Castel et al. 2008).

Reactive oxygen species (ROS) are assumed to be the main downstream actors to PA in pathogen-induced signalling cascades (Zhang \& Xiao 2015). Although it was demonstrated that PLD-produced PA directly regulates the NADPH oxidase-dependent oxidative burst during a drought stress (Zhang et al. 2009), this link has not been clearly established with respect to pathogen-response. Firstly, is PA production a common signature of MTI, irrespective of the MAMP and the cell model? Secondly, can PA produced by DGK activities act upstream of the NADPH oxidase during plant-pathogen interactions? In this present work, we report on the regulatory function of DGK in controlling the cryptogein-induced oxidative burst in Bright Yellow-2 (BY-2) cell suspensions. Using biochemical, pharmacological and 
reverse genetic approaches, we show that PA, originating from a DGK coupled to PI-PLC, is an upstream positive regulator of the plasma membrane-localized NADPH oxidase isoform

137 RBOHD in response to cryptogein.

138 


\section{Culture conditions and cryptogein elicitation of tobacco cells}

141 Bright Yellow-2 (Nicotiana tabacum) cells were grown in modified liquid Murashige and 142 Skoog (MS, M0221, Duchefa-Kalys, Bernin, France) medium at pH 5.6 (M0221, Duchefa143 Kalys, Bernin, France) supplemented with $1 \mathrm{mg} . \mathrm{L}^{-1}$ thiamine-HCl, $0.2 \mathrm{mg} . \mathrm{L}^{-1} \quad 2,4$ 144 dichlorophenylacetic acid, $100 \mathrm{mg} . \mathrm{L}^{-1}$ myo-inositol, $30 \mathrm{~g} . \mathrm{L}^{-1}$ sucrose, $200 \mathrm{mg} . \mathrm{L}^{-1} \mathrm{KH}_{2} \mathrm{PO}_{4}$ and 1452 g.L $L^{-1}$ MES. Cells were maintained under continuous light $\left(200 \mu \mathrm{E} \mathrm{m}^{-2} \mathrm{~s}^{-1}\right)$ on a rotary shaker 146 (140 rpm) and sub-cultured to fresh medium (4:80, (v/v)) on a weekly basis.

For radiolabeling experiments, ROS quantification and pharmacological treatments, cells were harvested from 7-day-old suspensions using a vacuum-system and resuspended at $0.1 \mathrm{~g} / \mathrm{mL}$ in either equilibration medium $\mathrm{I} 2$ (2 mM MES, $175 \mathrm{mM}$ mannitol, $0.5 \mathrm{mM} \mathrm{CaCl}_{2}$, $\left.0.5 \mathrm{mM} \mathrm{K}_{2} \mathrm{SO}_{4}, \mathrm{pH} 5.9\right)$ or I20 (20 mM MES, $175 \mathrm{mM}$ mannitol, $0.5 \mathrm{mM} \mathrm{CaCl} 2,0.5 \mathrm{mM}$ $\mathrm{K}_{2} \mathrm{SO}_{4}, \mathrm{pH}$ 5.9). After a $3 \mathrm{~h}$ incubation period under mild shaking at $24^{\circ} \mathrm{C}$, cells were elicited by adding $50 \mathrm{nM}$ cryptogein (final concentration) from a solution prepared according to (Ricci et al. 1989).

\section{Radiolabelling experiments}

BY-2 cells were aliquoted $(7 \mathrm{~mL})$ in wide neck flasks (capacity $50 \mathrm{~mL}$ ) for equilibration. Cells were then labelled by the addition of $53 \mathrm{MBq} \cdot \mathrm{L}^{-1}\left[{ }^{33} \mathrm{P}\right]$-orthophosphate. Total lipids were extracted according to the procedure previously described by (Krinke et al. 2009). Lipids were separated by thin layer chromatography (TLC) and developed either in an acidic solvent system composed of chloroform:acetone:acetic acid:methanol:water (10:4:2:2:1, (v/v), Lepage 1967) or in a solvent system composed of an upper phase of ethyl acetate:isooctane:acetic acid: water (12:2:3:10 (v/v), Munnik et al. 1995). Radiolabelled spots 
were quantified by autoradiography using a Storm phosphorimager (Amersham Biosciences, Buckinghamshire, UK). Separated phospholipids were identified by co-migration with authentic non-labelled standards visualized by primuline staining (under UV light) or by phosphate staining.

\section{Quantification of reactive oxygen species}

Reactive oxygen species were measured using a luminol-based method as described previously (Simon-Plas et al. 2002) but with slight modifications. Briefly, after a 3 hequilibration period in I20 medium, cells were treated with cryptogein. Before elicitation, samples corresponding to zero time were harvested and the luminescence background of the assay was measured. Samples $(250 \mu \mathrm{L})$ were regularly harvested over the first $90 \mathrm{~min}$ for ROS determination using a luminometer (Lumat LB9507, Berthold Technologies, Bad Wilbad, Germany). Fifty microliters of a $0.3 \mathrm{mM}$ luminol solution and $300 \mu \mathrm{L}$ of the assay buffer (50 mM MES, $175 \mathrm{mM}$ mannitol, $0.5 \mathrm{mM} \mathrm{CaCl}_{2}, 0.5 \mathrm{mM} \mathrm{K}_{2} \mathrm{SO}_{4}, \mathrm{pH}$ 6.5) were automatically added to cell aliquots before luminescence was measured (delay in injection of $1.2 \mathrm{~s}$, data acquisition time of $10 \mathrm{~s}$ ). For each biological and technical replicates, $2 \mathrm{~h}$ after elicitation (when the oxidative burst was over), a calibration curve was made in order to convert relative luminescence units (RLU) into $\mathrm{H}_{2} \mathrm{O}_{2}$ equivalents by recording cell luminescence upon the addition of increasing $\mathrm{H}_{2} \mathrm{O}_{2}$ concentrations during the assay. Results were normalized to BY-2-cell weight and expressed as nmoles $\mathrm{H}_{2} \mathrm{O}_{2}$ equivalents per gram of cells.

\section{Reverse transcription-quantitative polymerase chain reaction}

RNA extraction, reverse transcription and quantitative measurement of gene expression by QPCR were carried out as described by (Anca et al. 2014). Two reference genes were used for

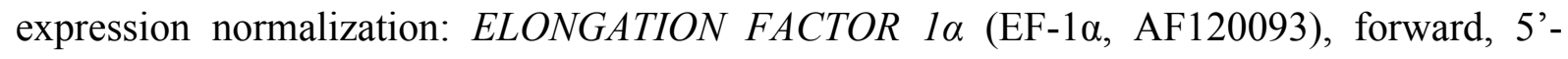


TGAGATGCACCACGAAGCTC-3', and reverse, 5'-CCAACATTGTCACCAGGAAGTG3'; and L25 gene coding for a ribosomal subunit (L18908), forward, 5'CCCCTCACCACAGAGTCTGC-3', and 5'AAGGGtGtTGtTGtCCTCAATCTT-3'. Primer sequences for NtDGK5-like gene are as follows: NtDGK5-like specific couple: forward (F85sq), 5'AGTCCGAGCTCAATGACAACA-3'; and reverse (R85sq2), 5'GTACGAAGAAGTTCTCCTCCAAGTT-3'; Cluster III gene-targeting couple: forward (ClusterIII-F), 5'-TTCAGCATGGGGATGGATGCA-3'; and reverse (ClusterIII-R), 5'AACCATCCTTGYGTACATCC-3'

\section{Cloning of NtDGK5-like coding sequence}

NtDGK5-like coding sequence was amplified by PCR from cDNA obtained from untreated 7day-old BY-2 cells using high fidelity DNA polymerase (Phire Hot Start, ThermoFisher SCIENTIFIC) and specific primers: forward (F1c85), 5'-ATGGCGAATTCTGAGTCCGA3'; and reverse (R1c85), 5'-CTAACTGAGACGAGAAACATCGA-3'. Primers were designed according to the sequence of SGN-U439985 (Solanacea Genomic Network database). Resulting PCR products were cloned into pSC-B Amp/Kan vector using the topoisomerase-based StrataClone Blunt PCR cloning kit (Agilent). Seven clones were sequenced among which one was selected for further work. The sequence was deposited in GenBank (accession number KU934207). This cDNA was named NtDGK5-like because its closest Arabidopsis thaliana ortholog is AtDGK5.

\section{Production of overexpressing NtDGK5-like transgenic lines}

The NtDGK5-like coding sequence was first amplified by PCR using high fidelity DNA polymerase from $p S C$-B::DGK5-like using the following primer pairs: couple 1, forward (CACC-F85), 5'-CACCATGGCGAATTCTGAGTCCGA-3'; and the reverse R1c85; couple 

CTAGAGGTCTTCTTCGCTGATGAGCTTTTGTTCACTGAGACGAGAAACATCGAC-

3'. Two independent intermediate constructs to express a C-terminally c-myc tagged protein

213 and an untagged version were generated by cloning the PCR products into $\mathrm{pENTR/D-TOPO}$ (ThermoFisher SCIENTIFIC). Sequencing of both inserts revealed no mutations. Using Gateway LR Clonase II enzyme mix (ThermoFisher SCIENTIFIC), MluI-digested pENTR/D::DGK5-like-c-myc and MluI-digested pENTR/D::DGK5-like were then independently recombined with pMDC32 (Karimi et al. 2007) to generate plant-expressing vectors that were checked for correct recombination by restriction digestions before being used to transform WT BY-2 cell suspensions following a previously described procedure (Simon-Plas et al. 2002). Among the 6 hygromycin-resistant calli isolated, only one overexpressed the untagged version of NtDGK5-like (named line OE.NtDGK5-A) while five out of twenty hygromycin-resistant calli overexpressed the C-terminally tagged version of NtDGK5-like. The two lines, named OE.NtDGK5myc-A and OE.NtDGK5myc-B, which exhibited the strongest levels of transgene expression, were selected for further characterization.

\section{Generation of cluster III DGK-silenced cell lines}

A conserved region of cluster III DGKs of the NtDGK5-like coding sequence, from nucleotides 511 to 692 (see supporting information Fig. S2) was chosen to be inserted into the post-transcriptional gene silencing vector (pH7GWIWG2(II), Karimi et al. 2007). This fragment was PCR-amplified using high fidelity DNA polymerase and the following specific primers: forward (Fc-ClusterIII), 5'-CACCTCATTTTTGAAGCAAGTAATGAATGCA-3', and reverse (Rc-ClusterIII), 5'-TGGAAACCTTCCACATTCAGTTCA-3'. The resulting PCR product was directionally cloned into $\mathrm{pENTR/D-TOPO}$ and the $p E N T R:: D G K 5$-like fragment was sequenced before the plasmid was recombined with pH7GWIWG2(II). The final 
construct was verified by restriction digestion and the fragment-intron loop-fragment was also sequenced. To check that the construct was functional, a transient tobacco expression system was designed (explained hereafter). Wild-type (WT) BY-2 cells were transformed as previously described (Simon-Plas et al. 2002). Among the 30 hygromycin-resistant calli isolated, 5 were screened and 2 independent transgenic lines (named $h p$-clusterIII- $A$ and $h p$ clusterIII-B lines) silenced for NtDGK5-like were identified and selected for further characterization.

\section{Transient expression system in tobacco plants}

To test for functional miRNA constructs, Agrobacterium tumefaciens (GV3101) were transformed with the Cluster III-targeting vector and selected clones were grown overnight under mild shaking at $28^{\circ} \mathrm{C}$ in regular Luria-Bertani medium containing $50 \mu \mathrm{g} . \mathrm{mL}^{-1}$ rifampicin, $50 \mu \mathrm{g} \cdot \mathrm{mL}^{-1}$ gentamycin and $50 \mu \mathrm{g} \cdot \mathrm{mL}^{-1}$ spectinomycin. Bacteria were collected the following day by centrifugation and the pellets were resuspended in induction buffer (20 mM MES pH 5.5, $10 \mathrm{mM}$ MgSO4, $200 \mu \mathrm{M}$ acetosyringone) so that the $\mathrm{OD}_{600 \mathrm{~nm}}$ was $0.5-0.6$. After incubation at room temperature for $3 \mathrm{~h}$, the bacterial suspension was infiltrated into the abaxial side of detached tobacco leaves (Nicotiana tabaccum, 4 to 6 week-old plants) using a needleless syringe. Samples for RT-PCR were harvested 2 days-post inoculations. Each experiment included non-infiltrated and infiltrated leaf material with bacterial clones containing the empty vector as controls. Stem-loop reverse transcription reactions to show specific pri-miRNA was performed on 2 independent biological replicates according to (Chen 2005)

using the following

primer: 5'GTCGTATCCAGTGCAGGGTCCGAGGTATTCGCACTGGATACGACtggaaac-3'; the underscored sequence corresponding to the gene specific part of the primer whereas the other part corresponds to the stem-loop backbone of the microRNA miR172 (Martin et al. 2009). Stem-loop RT controls were carried out using a 5S-rRNA-specific oligonucleotide 5'- 

generated cDNA matrix was amplified by regular PCR with a gene specific-forward primer and a miR172 reverse primer (5'-GGGTCGACATCAAGTCATCAATTTGCCA-3'). For the 5S-rRNA template, the forward primer was as follows: 5S-rRNA-F, 5'GGATGCGATCATACCAGCACT-3'; for the Cluster III-targeting miRNA, the primer used for generating the construct (Fc-ClusterIII, described above) was used. PCR products were then sequenced and proved to correspond to Cluster III pri-miRNA.

\section{Western blot analysis}

Seven-day old cells from the OE.NtDGK5myc-A and OE.NtDGK5myc-B lines and the corresponding empty vector line were harvested by filtration and protein extracts (cytosol, microsomes and plasma membrane) were prepared as described by (Mongrand et al. 2004). Proteins were solubilized in a buffer containing $40 \mathrm{mM}$ Tris- $\mathrm{HCl} \mathrm{pH} 6.8,5 \% \quad \beta-$ mercaptoethanol, 1.5\% SDS, $1 \mathrm{mM}$ EDTA, 2M urea, 1M thiourea, 1\% n-octyl-glucoside, $10 \%$ glycerol and bromophenol blue for $2 \mathrm{~h}$ at room temperature, separated by SDS-PAGE $(8 \%(\mathrm{w} / \mathrm{v})$ acrylamide-bisacrylamide) and transferred onto nitrocellulose membrane (Hybond ECL; GE Healthcare, Chalfont St Giles, UK). The membrane was blocked overnight in a 5\% $(\mathrm{w} / \mathrm{v})$ milk solution and probed with an anti-c-myc antibody directly coupled to horseradish peroxidase (GenScript, Piscataway, New Jersey, USA). Specific signals were revealed using an ECL kit (Perkin Elmer, Waltham, MA, USA) according to the manufacturer's instructions.

\section{Assessment of cell suspension density}

The packed cell volume (PCV) and dry weight (DW) were used as proxies of cell density. PCV was determined upon centrifugation of $15 \mathrm{~mL}$ cell suspension samples ( $700 \mathrm{x} \mathrm{g}, 3 \mathrm{~min})$. It represents the ratio of pelleted cell volume to the total sample volume, expressed in percent 
$28455^{\circ} \mathrm{C}$ for 3 days; a condition that allows the culture medium to fully evaporate. It is expressed 285 in percent with reference to WT BY-2 conditions set to 100.

\section{Phylogenetic analysis}

287 Sequence alignment and phylogenetic tree building were carried out as described previously 288 (Cacas et al. 2011). 
The MAMP cryptogein triggers rapid accumulation of phosphatidic acid in tobacco BY-

\section{2 cell suspensions}

The potential production of PA following elicitation of BY-2 tobacco cell suspensions with cryptogein was investigated by treating cells with the peptide and extracting lipids for up to one hour after elicitor addition. Cells were incubated with $\left[{ }^{33} \mathrm{Pi}\right]$-orthophosphate for $20 \mathrm{~min}$ before lipid extraction and $\left[{ }^{33} \mathrm{P}\right]$-labelled PA levels were measured after lipid separation by thin layer chromatography (TLC). Marked changes in labelled PA levels were observed after the addition of cryptogein (Fig. 1a) and quantification of the signal showed that after a 3 min lag, radiolabelled PA increased and reached a maximum within the first $10 \mathrm{~min}$ and then plateaued (Fig. 1b).

\section{PLC and DGK inhibitors reduce the accumulation of phosphatidic acid in response to} cryptogein

Under our experimental conditions, i.e. short-time radioisotopic labelling, the main pool of radiolabel is incorporated into ATP whereas structural phospholipids are only weakly labelled. This experimental design is commonly used to detect in vivo activity of lipid kinases, including DGKs, because these enzymes use the $\gamma$-phosphate group of ATP as their substrate. Hence, it could be postulated from our data that, in response to cryptogein, a phospholipase C activity produced DAG that was then processed by DGK into PA. These two hypotheses were tested by a pharmacological approach relying on the use of edelfosine, an inhibitor of phosphoinositide-dependent PLC (PI-PLC; Wong et al. 2007; Kelm et al. 2010; Djafi et al. 2013) and R59022, an inhibitor of DGK (Gómez-Merino et al. 2004). Wild-type cell suspensions were preincubated with inhibitors and radioactivity incorporated into PA was quantified 10 min after cryptogein addition, i.e. when PA levels are maximal. Edelfosine was 
found to significantly alter cryptogein-induced PA accumulation in a dose-dependent manner, leading to a maximum inhibition of radioactive PA production of around $70 \%$ (Fig. 2a). Furthermore, $75 \mu \mathrm{M}$ R59022 provoked a similar decrease of radioactive PA accumulation (Fig. 2b).

It was shown in Arabidopsis thaliana that phosphoinositides, substrates of PI-PLCs, are provided by type III-phosphatidylinositol-4 kinases (PI4K) that are sensitive to micromolar concentrations of wortmannin (Delage et al. 2012, Djafi et al. 2013). Pre-treatment of BY-2 cells with $30 \mu \mathrm{M}$ wortmannin resulted in a $46 \%$ inhibition of cryptogein-induced PA accumulation whereas $1 \mu \mathrm{M}$ of the inhibitor, a concentration that represses phosphatidylinositol-3 kinase activity (Krinke et al. 2007) but not that of PI4K, did not exhibit any effect (Fig. 2c). Furthermore, since PI-PLC activity is highly dependent on calcium (Hunt et al. 2004, Pokotylo et al. 2014), lanthanides that can act as inhibitors of plasma membrane calcium channels (Tester 1990, Knight et al. 1997) were tested for their ability to impact PA production upon elicitation. As expected, increasing concentrations of $\mathrm{La}^{3+}$ led to decreasing PA accumulation in response to cryptogein (Fig. 2d).

Taken together, these findings clearly point to a role for a PI-PLC/DGK pathway in cryptogein-induced PA production in BY-2 tobacco cell cultures.

\section{PLC and DGK inhibitors diminish RBOHD-mediated oxidative burst intensity in}

\section{response to cryptogein}

Among early signalling events triggered by cryptogein in BY-2 cells is the RBOHD-mediated oxidative burst which takes place within the first $10-15$ min following elicitation and is, therefore, concomitant to the onset of PA production. To examine the hypothesis that a PIPLC/DGK pathway could control the oxidative burst, a pharmacological approach was undertaken. The exogenous application of the PI-PLC inhibitor edelfosine was found to 
drastically alter the cryptogein-induced oxidative burst (Fig. 3a), resulting in a $70 \%$ decrease of the total amount of ROS when compared to untreated WT cells (Fig. 3b). Similarly, treatment with the DGK inhibitor R59022 also promoted a significant decrease in ROS levels (Fig. 3c,d). Interestingly, neither PI-PLC nor DGK inhibitors led to the inhibition of extracellular $\mathrm{pH}$ alkalization, another early signalling event associated with cryptogein elicitation (Supporting information Fig. S3). As the results of both PA production and ROS burst supported a working scenario where a PI-PLC/DGK pathway controls the cryptogeininduced signalling cascade, a reverse genetic strategy was developed to identify DGK candidates involved in the regulation of RBOHD.

\section{Phylogenetic clustering of the tobacco diacylglycerol kinase family}

Tobacco DGK nucleotide sequences were retrieved by both a keywords and a sequence homology search with coding sequences of the seven identified Arabidopsis thaliana DGK genes and those published for rice (Oryza sativa) and tomato (Solanum lycopersicum) (Snedden \& Blumwald 2000, Zhang et al. 2008) using the BLAST algorithm of the Solanacea Genomics Network (SGN) server. No unigene could be identified, but 16 partial contigs were isolated (Supporting information Fig. S4). Manual EST and contig assembly led to the identification of two potential full-length mRNAs corresponding to the accessions SGNU440091 and SGN-U439985. A phylogenetic tree was built using the longest in silico translated tobacco primary amino acid sequences, including SGN-U440091, SGN-U439985 and 7 additional partial coding sequences, in addition to Arabidopsis, rice and tomato sequences (Fig. 4a).

DGKs are bipartite proteins composed of one catalytic domain and one accessory domain, assumed to be necessary for the kinase activity. While the animal DGK family can be subdivided into 5 classes (Goto \& Kondo 2004), plant DGKs only form three phylogenetic 
clusters characterized by distinct protein structures (Fig. 4a). Cluster I encompasses the closest sequence orthologous of metazoan enzymes with proteins that display in their Nterminus one or two DAG-binding domain(s) (noted C1) and either one or no transmembrane helix (Vaultier et al. 2008). Contrary to Cluster II DGKs that have a minimal DGK structure, cluster III DGKs can exhibit a C-terminal calmodulin binding region (referred to as CBD) depending on splicing variants (Arisz et al. 2009). SGN-U440091 and SGN-U439985 appear to belong to clusters II and III, respectively. Furthermore, amongst the 7 partial tobacco DGK coding sequences that were retrieved, four are present in cluster I, one in cluster II and two in cluster III.

\section{Overexpressing a member of the phylogenetic cluster III, NtDGK5-like, does not result} in a gain-of-function

Among tobacco cluster III members, the full-length cDNA corresponding to the unigene SGN-U439985 (hereafter referred to as NtDGK5-like after its closest Arabidopsis thaliana ortholog) was cloned and deposited in GenBank (Accession number KU934207). The isolated NtDGK5-like cDNA corresponds to a 1482 bp-long coding sequence that encodes a 493 amino acid protein displaying a molecular weight of $55.24 \mathrm{kDa}$ and a theoretical $\mathrm{pI}$ of 6.75 , with no predicted signal peptide. The NtDGK5-like gene is constitutively expressed in BY-2 cells but its expression is significantly up-regulated in response to cryptogein (Fig. 4b). Using transgenic lines overexpressing a C-terminal c-myc-tagged NtDGK5-like protein (named $O E . N t D G K 5 m y c-A$ and $O E . N t D G K 5 m y c-B$ lines), a cell fractioning approach was developed to identify where the protein was located. Cytosolic, microsomal and plasma membrane fractions were isolated and their proteins analysed by western blotting. The tagged protein was found in both the endomembrane and plasma membrane fractions (Fig. 4c). 
To study the role of NtDGK5-like, the two OE.NtDGK5myc-A and B lines were analysed further along with a third line (named $O E . N t D G K 5-A$ ) allowing the expression of an untagged NtDGK5-like protein under the control of the CaMV35S promoter. Despite a constitutive 10to-15-fold increase in steady-state levels of NtDGK5-like transcripts with respect to endogenous gene expression (Fig. 5a), all three overexpressor lines accumulated PA levels comparable to those of WT BY-2 and an empty vector-containing cell line in response to cryptogein (Fig. 5b). Accordingly, no differences in ROS production could be seen between overexpressing lines and WT or empty vector-control genotypes (Fig. 5c), with the notable exception of the $O E . N t D G K 5 m y c-B$ line. This line displays a significant difference with the WT line, but not with the empty vector control line. Because cryptogein-induced oxidative burst intensity was assessed on 7-day-old cell suspensions in our experimental system, the impact of overexpressing NtDGK5-like on cell density was estimated at this time-point. Packed cell volume (PCV) and dry weight (DW) of overexpressing lines were measured as two independent proxies of biomass and compared to those of WT cell culture. Only the OE.NtDGK5myc-B line had a slight defect in cell size (Fig. 5d) and this could explain the small but significant decrease in ROS levels produced upon elicitation.

\section{Silencing the phylogenetic cluster III DGK family of tobacco strongly inhibits}

\section{cryptogein-induced oxidative burst}

In an attempt to specifically silence NtDGK5-like gene expression, a miRNA transgenic cell line strategy was developed but it was unsuccessful due to the early death of transformed calli. However, to get insights into the function of cluster III DGKs, a construct targeting a conserved DNA region of cluster III members was engineered. A $180 \mathrm{bp}$-long portion of the NtDGK5-like coding sequence was cloned into the hairpin vector pH7GWIWIG2(II) (Fig. 6a). Using an Agrobacterium-mediated transient expression system, this construct was shown to produce DGK specific miRNA in planta (Fig. 6b) and it was therefore used to generate stable 
transgenic cell lines in the WT BY-2 genetic background. Amongst the 30 transformed clones obtained, two independent lines (named $h p$-clusterIII- $A$ and $h p$-clusterIII- $B$ lines) were identified and selected on the basis of their reduced constitutive expression of NtDGK5-like. While an empty vector-containing line displayed slightly higher levels of expression compared to the WT cell line, miRNA cell lines exhibited similar lower steady state-levels of NtDGK5-like transcripts, averaging 30 to $40 \%$ of that of WT cells (Fig. 6c). To test whether the expression of other cluster III DGK genes were affected in the two transgenic lines, QPCR was carried out using primers that allowed to simultaneously amplify the coding sequences of each cluster III genes. In this way, it was found that the bulk expression of cluster III genes was not altered in $h p$-clusterIII-A line whereas it was silenced approximately 3-fold in line $h p$-clusterIII-B line (Fig. 6c). A 3-fold down-regulation of NtDGK5-like is propbably not enough to induce changes in the bulk expression of cluster III genes (see $h p$ clusterIII-A cell line). This implies that that NtDGK5-like is not the only cluster III isoform to be silenced in the $h p$-clusterIII-B line. On the contrary, this gene is likely to be the main cluster III-DGK isoform to be silenced in the hp-clusterIII-A cell line NtDGK5-like.

The impact of silencing DGK cluster III on cell density was estimated. No evidence for statistical differences between the four analysed genotypes (BY-2, empty vector line, $h p$ clusterIII- $A$ and $h p$-clusterIII-B lines) on PCV and DW at day 7 after sub-culturing was found (Fig. 6d). Hence, potential effects of cluster III silencing on both PA and ROS production was determined upon cryptogein elicitation. The $D G K$-silenced lines were shown to no longer over-accumulate PA, 10 min after cryptogein addition (Fig. 7a). Remarkably, the absence of early PA accumulation in these elicited transgenics could be correlated with a marked decrease in oxidative burst intensity. Wild-type and empty-vector lines showed a similar stereotyped behaviour characterized by a rapid and transient peak of ROS, being maximum within 10-15 min post-treatment before decreasing and stabilizing for the last $45 \mathrm{~min}$, whereas 
435 ROS profiles of the two hp-clusterIII- lines were devoid of a well-defined peak, exhibiting 436 rather weak and stable ROS levels over 90 min (Fig. 7b). Indeed, total levels of extracellular 437 ROS generated by the miRNA lines accounted for approximately one third to one half of 438 those recorded in WT and empty vector-containing lines upon cryptogein application (Fig. $4397 \mathrm{c})$. 
441 In the present work, radio-labelling experiments clearly showed that in vivo levels of PA 442 rapidly increased when BY-2 cell suspensions were challenged with cryptogein, reaching a maximum after $10 \mathrm{~min}$ and then staying stable during $1 \mathrm{~h}$. Under our experimental conditions, $\left[{ }^{33} \mathrm{Pi}\right]$-orthophosphate was added to cell cultures $20 \mathrm{~min}$ before lipid extraction. In contrast to long time periods of isotope incubation that lead to labelled structural phospholipids, short time labelling results in the incorporation of isotopic phosphorus into ATP. Hence, this setup is optimized to detect products of lipid kinases using ATP as substrate (Vaultier et al. 2006) and being active within the duration of labelling. These kinase activities include DGK and others, such as PI4-kinase and PI4P-5-kinase. Indeed, the radioactivity incorporated into PI4P is typically 4- to 5-fold that of PI, in control cells, although PIP (not labelled) is much less abundant than PI (Furt et al. 2010). However, this experimental design is not optimal for detecting the possible occurrence of PLD activity. The radioactivity associated with PA upon cryptogein treatment represented 3- to 4-fold of that monitored in phosphatidylcholine, phosphatidylethanolamine and phosphatidylglycerol, putative substrates of PLDs. This strongly supports the idea that radiolabelled PA found after a 20 min labelling cannot arise from PLD action. Yet, this does not mean a PLD is not activated upon cryptogein addition. A 457 long time labelling with $\left[{ }^{33} \mathrm{Pi}\right]$-orthophosphate (16 hours) designed to reveal PLD activity was 458 also carried out. In the presence of primary alcohol $n$-butanol, PLD catalyses a trans459 phosphatidylation reaction transferring the phosphatidyl moiety from structural lipids onto the hydroxyl group of the primary alcohol. In our hands, no radiolabeled phosphatidylbutanol accumulated in response to cryptogein (data not shown). However, since the signal-to-noise

462 ratio was low in these experiments, we cannot rule out the possible activation of PLD by 463 cryptogein. 
The fact that the increase in radiolabelled PA in our experimental design was due to DGK was indicated by the pharmacological approach where DGK inhibitors led to an inhibition of radiolabelled PA accumulation. Moreover, the inhibiting effects of wortmannin and edelfosine strongly suggest that the DAG substrate of DGK was produced by a PI-PLC activity, the substrate of which is provided by a type III PI4K. In Arabidopsis thaliana, it has been shown that PI-PLC substrates are provided by such PI4Ks, either for basal PI-PLC activity (i.e. active in control cell, Djafi et al. 2013) or during PI-PLC activation by chilling (Delage et al. 2012). Therefore it seems that the role of type III PI4Ks to supply substrates to PI-PLC is likely to be the case for other plant species, including tobacco. Besides, PI-PLCs are strictly dependent on calcium and therefore it was not surprising that a blocker of plasmalemma calcium channels, lanthanides, inhibited radioactive PA accumulation.

Since inhibitors of different chemical nature acting on different enzymes (PI4K, PI-PLC, DGK) of a given pathway led to a similar inhibition of cryptogein-induced accumulation of radiolabelled PA, it is unlikely that this is due to hypothetical side effects of each inhibitor (Djafi et al. 2013, Ruelland et al. 2014). Moreover, silencing the phylogenetic cluster III of tobacco DGKs resulted in the loss of the cryptogein-induced PA increase thus demonstrating unambiguously the involvement of such enzymes in this response to cryptogein. Our knowledge concerning plant DGKs is still limited. Prokaryotic DGKs exhibit a peculiar multimeric membrane-embedded structure with three transmembrane spanning-regions per subunit (Van Horn \& Sanders 2012). Metazoan counterparts display a conserved bidomain architecture associated with catalytic activity and decorated by a huge diversity of additional functional domains that are responsible for membrane or protein interactions and subcellular localization (Goto \& Kondo 2004). Predictions of plant DGK structures using the Conserved Domain Architecture Retrieval Tool (Geer et al. 2002) reveal a simpler organization that falls into three evolutionary phyla (Vaultier et al. 2008). In this work, we focused our efforts on 
DGKs of phylogenetic cluster III. Two members of this cluster have been either

490

491

492

493

494

495

496

497

498

499

500

501

502

503

504

505

506

507

508

509

510

511

512

513

biochemically or functionally characterized. The rice DGK1 was stably expressed in tobacco plants and found to confer enhanced disease resistance to tobacco mosaic virus (TMV) and to the oomycete Phytophthora infestans (Zhang et al. 2008). Two distinct spliced mRNA variants were reported for the tomato LeDGK1/CBK1-encoded gene and this transcriptional regulatory mechanism was demonstrated to regulate protein docking at the plasma membrane (Snedden \& Blumwald 2000) In addition, the AtDGK5 gene expression was found to be upregulated in response to flagellin 22, a bacterial MAMP, as well as several avirulent pathogens (GENEVESTIGATOR database, Hruz et al. 2008).

In this work, one member of cluster III was cloned and named NtDGK5-like after its closest Arabidopsis ortholog. Independent transgenic cell lines were generated that allowed constitutive overexpression of either native NtDGK5-like (OE.NtDGK5-A) or a C-terminally c-myc tagged version of the protein (OE.NtDGK5myc-A and $O E . N t D G K 5 m y c-B)$. Despite the absence of any predicted signal peptide and transmembrane domain, western-blotting established that the protein was localized to the plasma membrane, as already reported for a LeDGK1/CBK1 variant from tomato (Snedden \& Blumwald 2000). In all NtDGK5-like overexpressing lines the accumulation of radioactive PA after 10 min of cryptogein addition was similar to that of control and WT lines. Thus it is tempting to speculate that DGK is not a limiting step in the coupled reaction leading to PA in response to cryptogein.

Previously, we had established that early cryptogein-induced ROS synthesis was fully dependent on the isoform D of the RBOH family in BY-2 cell suspensions (Simon-Plas et al. 2002). In addition, Zhang et al. (2009) demonstrated that PA could directly interact with the Arabidopsis RBOHD isoform via an N-terminally-localized PA-binding domain and, subsequently, stimulate its activity. Alignment of the highly homologous tobacco RBOHD isoform with its Arabidopsis counterpart pinpointed that the location and sequence of the PA- 
binding domain, as well as the basic nature of the two amino acid residues involved in the interaction with PA, are conserved between the two plant species (Supporting information Fig S5). Both PI-PLC and DGK inhibitors reduced the RBOHD-dependent oxidative burst. Furthermore, transgenic lines deficient for the tobacco cluster III DGKs displayed a significantly reduced oxidative burst upon cryptogein addition. Such findings strongly point to a direct regulation of RBOHD activity by PA, and place the PI-PLC/DGK pathway upstream from the enzyme in a signalling cascade induced by the MAMP cryptogein. It can be postulated that at least one DGK member of cluster III is responsible for the required DGK activity. Even though our genetic strategy concerning NtDGK5-like was partly unsuccessful, this gene still remains a good candidate since it was the only cluster III DGK gene suppressed in the hp-clusterIII-A cell line.

Distinct regulatory mechanisms have been described for plant $\mathrm{RBOH}$ proteins. These include post-translational modifications like phosphorylation (Kobayashi et al. 2007, Ogasawara et al. 2008) and S-nitrosylation (Yun et al. 2011), association with RacGTPase (Wong et al. 2007b, Oda et al. 2010) as well as regulation by extracellular ATP level and calcium influx (Song et al. 2006, Demidchik et al. 2009). Zhang et al. (2009) also elegantly demonstrated that direct binding of PA activates AtRBOHD, in fine controlling stomatal aperture upon drought stress. Contrary to our model, where a PI-PLC/DGK pathway is involved, the authors showed that PLD 1 was the main source of PA under their experimental conditions. In the context of plant defence, whether it is MTI or ETI, to date there is no genetic evidence for a role of DGKs in the positive regulation of $\mathrm{RBOH}$ enzymes, even though it has been suggested previously by several works (de Jong et al. 2004, Andersson et al. 2006, Vossen et al. 2010). Instead, many reports indicate PLDs as the main suppliers of PA in response to MAMP/pathogen effectors, irrespective of the downstream protein target (Young et al. 1996, van der Luit et al. 2000, de Torres Zabela et al. 2002, Bargmann et al. 2006, Laxalt et al. 2007, Krinke et al. 2009, 
539 Yamaguchi et al. 2009, Kalachova et al. 2013, Zhao et al. 2013, Pinosa et al. 2013). Thus, our

540 work sheds light on new insights into regulatory mechanisms that control early signalling 541 events associated with NADPH oxidase since PA produced by a PI-PLC/DGK pathway can 542 also control NADH oxidase activity. As underlined by (Zhang \& Xiao 2015), this raises 543 interesting questions as to how the spatiotemporal regulation of PA neo-synthesis and the 544 engaged molecular species of PA could influence the specificity of downstream responses. 
547 This work was supported by the French National Research Agency (ANR, Programme Blanc 548 PANACEA NT09_517917), the Bordeaux Metabolome Facility-MetaboHUB (grant no. 549 ANR-11-INBS-0010 to S.M.) and platform Métabolome-Lipidome-Fluxome of Bordeaux 550 (contribution toward lipid analysis equipment). We would like to thank Dr. Olivier Lamotte 551 and Pr. Nathalie Leborgne-Castel for their support and stimulating discussions, and Dr 552 Michael Hodges, IPS2, Orsay France for carefully reading the manuscript. The authors have 553 no conflict of interest to declare.

554 AUTHOR'S CONTRIBUTION: JLC, PGP, JF, ER, CC, DT, TK \& KM carried out 555 experiments; FSP, SM, EJ, PGP, JLC \& ER designed experiments and discussed results; JLC, 556 PGP \& ER wrote the manuscript; SM \& FSP coordinated the project and retrieved ANR 557 funds. 
Anca I.A., Fromentin J., Bui Q.T., Mhiri C., Grandbastien M.A. \& Simon-Plas F. (2014) Different tobacco retrotransposons are specifically modulated by the elicitor cryptogein and reactive oxygen species. Journal of Plant Physiology 171, 1533-1540.

Andersson M.X., Kourtchenko O., Dangl J.L., Mackey D. \& Ellerström M. (2006) Phospholipase-dependent signalling during the AvrRpm1- and AvrRpt2-induced disease resistance responses in Arabidopsis thaliana. The Plant Journal 47, 947-959.

Arisz S.A., Testerink C. \& Munnik T. (2009) Plant PA signaling via diacylglycerol kinase. Biochimica et biophysica acta 1791: 869-875.

Bargmann B.O.R., Laxalt A.M., Riet B.T., Schouten E., van Leeuwen W., Dekker H.L., ..., Munnik T. (2006) LePLDbetal activation and relocalization in suspension-cultured tomato cells treated with xylanase. The Plant Journal 45, 358-368.

Bigeard J., Colcombet J. \& Hirt H. (2015) Signaling Mechanisms in Pattern-Triggered Immunity (PTI). Molecular Plant 8, 521-539.

Blein J.P., Milat M.L. \& Ricci P. (1991) Responses of Cultured Tobacco Cells to Cryptogein, a Proteinaceous Elicitor from Phytophthora cryptogea: Possible Plasmalemma Involvement. Plant Physiology 95, 486-491.

Bruntz R.C., Taylor H.E., Lindsley C.W. \& Brown H.A. (2014) Phospholipase D2 mediates survival signaling through direct regulation of Akt in glioblastoma cells. The Journal of Biological Chemistry 289, 600-616.

Cacas J.-L. (2015) Out for a Walk Along the Secretory Pathway During Programmed Cell Death. In: Gunawardena AN, McCabe PF (eds) Plant Programmed Cell Death 123-161. 
Springer International Publishing, Cham.

582

583

584

585

586

587

588

589

590

591

592

593

594

595

596

597

598

599

600

601

602

Cacas J.-L., Petitot A.-S., Bernier L., Estevan J., Conejero G., Mongrand S. \& Fernandez D. (2011) Identification and characterization of the Non-race specific Disease Resistance 1 (NDR1) orthologous protein in coffee. BMC Plant Biology 11, 144.

Cacas J.-L., Vailleau F., Davoine C., Ennar N., Agnel J.-P., Tronchet M., .., Montillet J.-L. (2005) The combined action of 9 lipoxygenase and galactolipase is sufficient to bring about programmed cell death during tobacco hypersensitive response. Plant, Cell and Environment 28,1367-1378.

Canton J. \& Grinstein S. (2014) Priming and activation of NADPH oxidases in plants and animals. Trends in Immunology 35, 405-407.

Chen C. (2005) Real-time quantification of microRNAs by stem-loop RT-PCR. Nucleic Acids Research 33, e179-e179.

Dahan J., Pichereaux C., Rossignol M., Blanc S., Wendehenne D., Pugin A. \& Bourque S. (2009) Activation of a nuclear-localized SIPK in tobacco cells challenged by cryptogein, an elicitor of plant defence reactions. Biochemical Journal 418, 191-200.

Dangl J.L. \& Jones J.D. (2001) Plant pathogens and integrated defence responses to infection. Nature 411, 826-833.

Delage E., Ruelland E., Guillas I., Zachowski A. \& Puyaubert J. (2012) Arabidopsis Type-III Phosphatidylinositol 4-Kinases $\beta 1$ and $\beta 2$ are Upstream of the Phospholipase C Pathway Triggered by Cold Exposure. Plant \& Cell Physiology 53, 565-576.

Demidchik V., Shang Z., Shin R., Thompson E., Rubio L., Laohavisit A., ..., Davies J.M.. (2009) Plant extracellular ATP signalling by plasma membrane NADPH oxidase and Ca 
Djafi N., Vergnolle C., Cantrel C., Wietrzynski W., Delage E., Cochet F., ..., Ruelland E. (2013) The Arabidopsis DREB2 genetic pathway is constitutively repressed by basal phosphoinositide-dependent phospholipase $\mathrm{C}$ coupled to diacylglycerol kinase. Frontiers in Plant Science 4: 307.

Dong W., Lv H., Xia G. \& Wang M. (2012) Does diacylglycerol serve as a signaling molecule in plants? Plant Signaling \& Behavior 7, 472-475.

Furt F., König S., Bessoule J.-J., Sargueil F., Zallot R., Stanislas T., ..., Mongrand S. (2010) Polyphosphoinositides are enriched in plant membrane rafts and form microdomains in the plasma membrane. Plant Physiology 152, 2173-2187.

Gajate C. \& Mollinedo F. (2015) Lipid rafts and raft-mediated supramolecular entities in the regulation of CD95 death receptor apoptotic signaling. Apoptosis 20, 584-606.

Geer L.Y., Domrachev M., Lipman D.J. \& Bryant S.H. (2002) CDART: protein homology by domain architecture. Genome Research 12, 1619-1623.

Gerbeau-Pissot P., Der C., Thomas D., Anca I.-A., Grosjean K., Roche Y., ..., Simon-Plas F (2014) Modification of Plasma Membrane Organization in Tobacco Cells Elicited by Cryptogein. Plant Physiology 164, 273-286.

Gómez-Merino F.C., Brearley C.A., Ornatowska M., Abdel-Haliem M.E.F., Zanor M.-I. \& Mueller-Roeber B. (2004) AtDGK2, a novel diacylglycerol kinase from Arabidopsis thaliana, phosphorylates 1-stearoyl-2-arachidonoyl-sn-glycerol and 1,2-dioleoyl-snglycerol and exhibits cold-inducible gene expression. The Journal of Biological Chemistry 279, 8230-8241. 
625

626

627

628

629

630

631

632

633

634

635

636

637

638

639

640

641

642

643

644

645

Goto K. \& Kondo H. (2004) Functional implications of the diacylglycerol kinase family. Advances in Enzyme Regulation 44, 187-199.

den Hartog M. (2003) Nod Factor and Elicitors Activate Different Phospholipid Signaling Pathways in Suspension-Cultured Alfalfa Cells. Plant Physiology 132, 311-317.

Hawkins P.T. \& Stephens L.R. (2015) PI3K signalling in inflammation. Biochimica et Biophysica Acta 1851, 882-897.

Hou Q., Ufer G. \& Bartels D. (2015) Lipid signalling in plant responses to abiotic stress. Plant, Cell and Environment 39,1029-1048.

Hruz T., Laule O., Szabo G., Wessendorp F., Bleuler S., Oertle L., ..., Zimmermann P (2008) Genevestigator v3: a reference expression database for the meta-analysis of transcriptomes. Advances in bioinformatics 2008, 420747.

Hunt L., Otterhag L., Lee J.C., Lasheen T., Hunt J., Seki M., .., Gray J.E. (2004) Genespecific expression and calcium activation of Arabidopsis thaliana phospholipase C isoforms. New Phytologist 162, 643-654.

Janda M., Planchais S., Djafi N., Martinec J., Burketova L., Valentova O., ..., Ruelland E. (2013) Phosphoglycerolipids are master players in plant hormone signal transduction. Plant Cell Reports 32, 839-851.

Johansson O.N., Fahlberg P., Karimi E., Nilsson A.K., Ellerström M. \& Andersson M.X. (2014) Redundancy among phospholipase D isoforms in resistance triggered by recognition of the Pseudomonas syringae effector AvrRpm1 in Arabidopsis thaliana. Frontiers in Plant Science 5, 639. 
647

648

649

650

651

652

653

654

655

656

657

658

659

660

661

662

663

664

665

666

667

668

de Jong C.F., Laxalt A.M., Bargmann B.O.R., de Wit P.J.G.M., Joosten M.H.A.J. \& Munnik T. (2004) Phosphatidic acid accumulation is an early response in the Cf-4/Avr4 interaction. The Plant Journal 39, 1-12.

Kalachova T., Iakovenko O., Kretinin S. \& Kravets V. (2013) Involvement of phospholipase $\mathrm{D}$ and NADPH-oxidase in salicylic acid signaling cascade. Plant Physiology and Biochemistry 66, 127-133.

Karimi M., Depicker A. \& Hilson P. (2007) Recombinational Cloning with Plant Gateway Vectors. Plant Physiology 145, 1144-1154.

Keller H., Blein J.P., Bonnet P. \& Ricci P. (1996) Physiological and Molecular Characteristics of Elicitin-Induced Systemic Acquired Resistance in Tobacco. Plant Physiology 110, 365-376.

Kelm M.K., Weinberg R.J., Criswell H.E. \& Breese G.R. (2010) The PLC/IP3R/PKC Pathway is Required for Ethanol-enhanced GABA Release. Neuropharmacology 58, $1179-1186$.

Knight H., Trewavas A.J. \& Knight M.R. (1997) Calcium signalling in Arabidopsis thaliana responding to drought and salinity. The Plant Journal 12, 1067-1078.

Kobayashi M., Ohura I., Kawakita K., Yokota N., Fujiwara M., Shimamoto K., ..., Yoshioka H. (2007) Calcium-dependent protein kinases regulate the production of reactive oxygen species by potato NADPH oxidase. The Plant Cell 19, 1065-1080.

Krinke O., Flemr M., Vergnolle C., Collin S., Renou J.-P., Taconnat L., ..., Ruelland E.. (2009) Phospholipase D activation is an early component of the salicylic acid signaling pathway in Arabidopsis cell suspensions. Plant Physiology 150, 424-436. 
Krinke O., Ruelland E., Valentová O., Vergnolle C., Renou J.-P., Taconnat L., ..., Zachowski A. (2007) Phosphatidylinositol 4-kinase activation is an early response to salicylic acid in Arabidopsis suspension cells. Plant Physiology 144, 1347-1359.

Larkin M.A., Blackshields G., Brown N.P., Chenna R., McGettigan P.A., McWilliam H., ..., Higgins D.G. (2007) Clustal W and Clustal X version 2.0. Bioinformatics 23, 2947-2948.

Laxalt A.M., Raho N., Have A.T. \& Lamattina L. (2007) Nitric Oxide Is Critical for Inducing Phosphatidic Acid Accumulation in Xylanase-Elicited Tomato Cells. Journal of Biological Chemistry 282, 21160-21168.

Leborgne-Castel N., Lherminier J., Der C., Fromentin J., Houot V. \& Simon-Plas F. (2008) The Plant Defense Elicitor Cryptogein Stimulates Clathrin-Mediated Endocytosis Correlated with Reactive Oxygen Species Production in Bright Yellow-2 Tobacco Cells. Plant Physiology 146, 1255-1266.

Lepage M. (1967) Identification and composition of turnip root lipids. Lipids 2, 244-250.

van der Luit A.H., Piatti T., van Doorn A., Musgrave A., Felix G., Boller T. \& Munnik T. (2000) Elicitation of suspension-cultured tomato cells triggers the formation of phosphatidic acid and diacylglycerol pyrophosphate. Plant physiology 123, 1507-1516.

Martin A., Adam H., Diaz-Mendoza M., Zurczak M., Gonzalez-Schain N.D. \& Suarez-Lopez P. (2009) Graft-transmissible induction of potato tuberization by the microRNA miR172. Development 136, 2873-2881.

Mongrand S., Morel J., Laroche J., Claverol S., Carde J.-P., Hartmann M.-A., ..., Bessoule J.-J..(2004) Lipid rafts in higher plant cells: purification and characterization of Triton X100-insoluble microdomains from tobacco plasma membrane. The Journal of Biological Chemistry 279, 36277-36286. 
Munnik T., Arisz S.A., De Vrije T. \& Musgrave A. (1995) G Protein Activation Stimulates Phospholipase D Signaling in Plants. The Plant cell 7, 2197-2210.

Oda T., Hashimoto H., Kuwabara N., Akashi S., Hayashi K., Kojima C., ..., Shimizu T. (2010) structure of the n-terminal regulatory domain of a plant NADPH Oxidase and its functional implications. Journal of Biological Chemistry 285, 1435-1445.

Ogasawara Y., Kaya H., Hiraoka G., Yumoto F., Kimura S., Kadota Y., .., Kuchitsu K. (2008) Synergistic activation of the Arabidopsis NADPH oxidase AtrbohD by Ca2+ and phosphorylation. The Journal of Biological Chemistry 283, 8885-8892.

Petroutsos D., Amiar S., Abida H., Dolch L.-J., Bastien O., Rébeillé F., ..., Maréchal E. (2014) Evolution of galactoglycerolipid biosynthetic pathways--from cyanobacteria to primary plastids and from primary to secondary plastids. Progress in Lipid Research 54, $68-85$.

Pinosa F., Buhot N., Kwaaitaal M., Fahlberg P., Thordal-Christensen H., Ellerström M. \& Andersson M.X. (2013) Arabidopsis phospholipase d $\delta$ is involved in basal defense and nonhost resistance to powdery mildew fungi. Plant Physiology 163, 896-906.

Pokotylo I., Kolesnikov Y., Kravets V., Zachowski A. \& Ruelland E (2014) Plant phosphoinositide-dependent phospholipases C: Variations around a canonical theme. Biochimie 96, 144-157.

Pokotylo I., Pejchar P., Potocký M., Kocourková D., Krčková Z., Ruelland E., ..,, Martinec J. (2013) The plant non-specific phospholipase C gene family. Novel competitors in lipid signalling. Progress in Lipid Research 52, 62-79.

Pugin A., Frachisse J.M., Tavernier E., Bligny R., Gout E., Douce R. \& Guern J. (1997) Early events induced by the elicitor cryptogein in tobacco cells: involvement of a plasma 
membrane NADPH Oxidase and activation of glycolysis and the pentose phosphate pathway. The Plant Cell 9, 2077-2091.

Ricci P., Bonnet P., Huet J.-C., Sallantin M., Beauvais-Cante F., Bruneteau M., ..., Pernollet J.-C. (1989) Structure and activity of proteins from pathogenic fungi Phytophthora eliciting necrosis and acquired resistance in tobacco. European Journal of Biochemistry $183,555-563$.

Ruelland E., Kravets V., Derevyanchuk M., Martinec J., Zachowski A. \& Pokotylo I. (2015) Role of phospholipid signalling in plant environmental responses. Environmental and Experimental Botany 114, 129-143.

Ruelland E., Pokotylo I., Djafi N., Cantrel C., Repellin A. \& Zachowski A. (2014) Salicylic acid modulates levels of phosphoinositide dependent-phospholipase C substrates and products to remodel the Arabidopsis suspension cell transcriptome. Frontiers in Plant Physiology 5, 608.

Rustérucci C., Montillet J.L., Agnel J.P., Battesti C., Alonso B., Knoll A., ..., Triantaphylidès C. (1999) Involvement of lipoxygenase-dependent production of fatty acid hydroperoxides in the development of the hypersensitive cell death induced by cryptogein on tobacco leaves. The Journal of Biological Chemistry 274, 36446-36455.

Sheng X., Yung Y.C., Chen A. \& Chun J. (2015) Lysophosphatidic acid signalling in development. Development 142, 1390-1395.

Simon-Plas F., Elmayan T. \& Blein J.-P. (2002) The plasma membrane oxidase NtrbohD is responsible for AOS production in elicited tobacco cells. The Plant Journal 31, 137-147.

Snedden W.A.\& Blumwald E. (2000) Alternative splicing of a novel diacylglycerol kinase in tomato leads to a calmodulin-binding isoform. The Plant Journal 24, 317-326. 
Song C.J., Steinebrunner I., Wang X., Stout S.C. \& Roux S.J. (2006) Extracellular ATP induces the accumulation of superoxide via NADPH oxidases in Arabidopsis. Plant Physiology 140, 1222-1232.

Stotz H.U., Mitrousia G.K., de Wit P.J.G.M. \& Fitt B.D.L. (2014) Effector-triggered defence against apoplastic fungal pathogens. Trends in Plant Science 19, 491-500.

Suzuki K.G.N. (2015) New insights into the organization of plasma membrane and its role in signal transduction. International Review of Cell and Molecular Biology 317; 67-96.

Tavernier E., Wendehenne D., Blein J.-P. \& Pugin A. (1995) Involvement of free calcium in action of cryptogein, a proteinaceous elicitor of hypersensitive reaction in tobacco cells. Plant Physiology 109, 1025-1031.

Tester M. (1990) Plant ion channels: whole-cell and single channel studies. New Phytologist $114,305-340$.

de Torres Zabela M., Fernandez-Delmond I., Niittyla T., Sanchez P. \& Grant M. (2002) Differential expression of genes encoding Arabidopsis phospholipases after challenge with virulent or avirulent Pseudomonas isolates. Molecular plant-microbe interactions $15,808-816$.

Van Horn W.D. \& Sanders C.R. (2012) Prokaryotic diacylglycerol kinase and undecaprenol kinase. Annual Review of Biophysics 41, 81-101.

Vaultier M.-N., Cantrel C., Guerbette F., Boutté Y., Vergnolle C., Ciçek D., ..., Ruelland E. (2008) The hydrophobic segment of Arabidopsis thaliana cluster I diacylglycerol kinases is sufficient to target the proteins to cell membranes. FEBS Letters 582, 1743-1748.

Vaultier M.-N., Cantrel C., Vergnolle C., Justin A.-M., Demandre C., Benhassaine-Kesri G., 

..., Ruelland E (2006) Desaturase mutants reveal that membrane rigidification acts as a cold perception mechanism upstream of the diacylglycerol kinase pathway in Arabidopsis cells. FEBS Letters 580, 4218-4223.

Vossen J.H., Abd-El-Haliem A., Fradin E.F., van den Berg G.C.M., Ekengren S.K., Meijer H.J.G., ..., Joosten M.H. (2010) Identification of tomato phosphatidylinositol-specific phospholipase-C (PI-PLC) family members and the role of PLC4 and PLC6 in HR and disease resistance. The Plant Journal 62, 224-239.

Wang G., Ryu S. \& Wang X. (2012) Plant phospholipases: an overview. Methods in molecular biology 861, 123-137.

Wong R., Fabian L., Forer A. \& Brill J.A. (2007a) Phospholipase C and myosin light chain kinase inhibition define a common step in actin regulation during cytokinesis. BMC Cell Biology 8, 15.

Wong H.L., Pinontoan R., Hayashi K., Tabata R., Yaeno T., Hasegawa K., ..., Shimamoto K. (2007b) Regulation of rice NADPH Oxidase by binding of Rac GTPase to Its N-terminal extension. The Plant Cell 19, 4022-4034.

Yamaguchi T., Kuroda M., Yamakawa H., Ashizawa T., Hirayae K., Kurimoto L., ..., Shibuya N (2009) Suppression of a phospholipase D gene, OsPLDbeta1, activates defense responses and increases disease resistance in rice. Plant Physiology 150, 308319.

Young S.A., Wang X. \& Leach J.E. (1996) Changes in the Plasma Membrane Distribution of Rice Phospholipase D during Resistant Interactions with Xanthomonas oryzae pv oryzae. The Plant Cell 8, 1079.

Yun B.-W., Feechan A., Yin M., Saidi N.B.B., Le Bihan T., Yu M., ..,, Loake G.J. (2011) S- 
nitrosylation of NADPH oxidase regulates cell death in plant immunity. Nature 478, 264-268.

785

786

787

788

789

790

791

792

793

794

795

796

797

798

Zhang W., Chen J., Zhang H. \& Song F. (2008) Overexpression of a rice diacylglycerol kinase gene OsBIDK1 enhances disease resistance in transgenic tobacco. Molecules and cells 26, 258-264.

Zhang Q. \& Xiao S. (2015) Lipids in salicylic acid-mediated defense in plants: focusing on the roles of phosphatidic acid and phosphatidylinositol 4-phosphate. Frontiers in Plant Science 6, 387.

Zhang Y., Zhu H., Zhang Q., Li M., Yan M., Wang R., ..., Wang X. (2009) Phospholipase dalphal and phosphatidic acid regulate NADPH oxidase activity and production of reactive oxygen species in ABA-mediated stomatal closure in Arabidopsis. The Plant cell $21,2357-2377$.

Zhao J., Devaiah S.P., Wang C., Li M., Welti R. \& Wang X. (2013) Arabidopsis phospholipase $\mathrm{D} \beta 1$ modulates defense responses to bacterial and fungal pathogens. The New Phytologist 199, 228-240. 
799 FIGURE LEGENDS

800 
801 Figure 1: Early accumulation of phosphatidic acid in response to cryptogein. Lipids were extracted at different time points after cryptogein addition. Cells were radiolabeled for $20 \mathrm{~min}$ before lipid extraction. (a) TLC plates were developed in an isooctane based solvent system. (b) The radioactivity associated with PA was quantified relative to the radioactivity associated 805 with all others phospholipids (PL) and then expressed as \% of the highest value. For each 806 point of the kinetics, 3 flasks of tobacco cells were treated independently with cryptogein. Data are mean $\pm \mathrm{SD}, n=3$. Note that the control error bars are within the symbol. 
810 DGK inhibitors. Edelfosine (a) and R50022 (b) were used as PI-PLC and DGK inhibitors, respectively. Wortmannin (c) and lanthanum (d) were used as type III-PI4K and calcium channel inhibitors, respectively. Cells were radiolabeled for $10 \mathrm{~min}$ and then cryptogein was

813 added. Lipids were extracted at 10 min after cryptogein addition. When necessary, inhibitors 814 were added 15 min before the cryptogein. Labelling was carried out during 20 min for each 815 point. Extracted lipids were separated using TLC plates and developed in an acidic solvent system. Radioactivity in PA spots was quantified relative to PE and results are expressed as \% of that in cryptogein treated cells. For each treatment, 3 flasks of tobacco cells were used to be 818 elicited or not with cryptogein in presence or not of inhibitors. The data are mean $\pm \mathrm{SD}, n=3$. 819 Results were analysed using a one-way ANOVA, with a Tukey honestly significant difference 820 (HSD) multiple mean comparison post hoc test. Different letters indicate a significant difference (Tukey HSD, $\mathrm{P}<0.05)$. 

inhibitors. Time course of ROS production of WT BY-2 cells pretreated with either R59022, an inhibitor of DGK activity (a), or edelfosine, an inhibitor of PLC activity (c). Total amounts of ROS produced over a 90 min period following elicitation were calculated for cell

827 suspensions treated with R59022 (b) or edelfosine (d). Cells were preincubated in I20 medium 828 for $30 \mathrm{~min}$ with the inhibitor at the indicated concentrations before cryptogein was added. 829 Extracellular ROS synthesis was regularly quantified using a luminol-based method. Data are 830 expressed as nmoles of $\mathrm{H}_{2} \mathrm{O}_{2}$ equivalents per gram of cells. Means and SD for 3 independent 831 replicates. Statistical difference for the total ROS level was assessed by a Student T-test, 832 where * indicates $\mathrm{P}<0.05$ and ** refers to $\mathrm{P}<0.01$. 
Figure 4: Phylogenetic clustering of tobacco DGKs and characterization of one member of cluster III. (a) Phylogenetic cluster of plant DGKs. Nucleic acid sequences were retrieved for DGKs from the Solanacea Genomics Network (SGN) database (https://solgenomics.net/) using the BLAST algorithm and keyword search tool. Known Arabidopsis, rice and tomato DGKs were used as nucleic acid sequence queries. The phylogenetic analysis was carried out using identified nucleic acid sequences (indicated by their SGN references) as previously described (Cacas et al. 2011). Plant DGKs were grouped into 3 phyla, each showing slightly different protein domain structures. Abbreviations: C1, C1 DAG binding domain; CBD, calmodulin-binding domain; DGKcat, DGK catalytic domain; DGKacc, DGK accessory domain. For plant species, At refers to Arabidopsis thaliana, Le to Solanum esculentum (previously Lycopersicum esculentum), Nt to Nicotiana tabacum and Os to Oryza sativa (b) Time course of NtDGK5-like gene expression in response to cryptogein. Gene expression was determined by Q-PCR as described in the Material and Methods. Data are means and SD for 3 independent biological replicates ( $\mathrm{n}=3$ samples per cell line). (c) Subcellular localization of NtDGK5-like protein. Cells from overexpressing NtDGK5-like-c-myc lines (OE.NtDGK5myc-A and OE.NtDGK5myc-B) and the corresponding empty vector-containing line (i.e. line transformed with an empty pMDC32) were harvested 7 days after subculture. Proteins were extracted from cytosolic (lanes 1), microsomal (lanes 2) and plasma membrane (lanes 3) fractions. After western blotting using anti-c-myc antibodies, a specific signal was only found in membrane fractions. Two independent biological replicates were carried out $(\mathrm{n}=2$ samples per cell line). 

Expression levels of NtDGK5-like overexpressing lines. Gene expression was determined by Q-PCR using primers that amplify both the endogenous and transgene-encoding transcripts.

Data are means and SD for 4 independent experiments. These experiments were carried out on material obtained from untreated 7-day-old cells. BY-2, WT cells; the empty vectorcontaining line is a BY-2 line transformed with an empty pMDC32; OE.NtDGK5-A, line overexpressing an untagged version of NtDGK5-like protein; OE.NtDGK5myc-A and OE.NtDGK5myc-B are independent lines overexpressing a C-terminally tagged version of NtDGK5-like protein. (b) Radioactivity associated with PA in cryptogein-elicited overexpressors. Cells were radiolabeled for $20 \mathrm{~min}$ before lipid extraction. Lipids were extracted 10 min after cryptogein addition. TLC plates were developed in an acid solvent system. The radioactivity associated with PA was normalized to that of PE and PC. The data are expressed as $\%$ of the value in the empty vector control line elicited with cryptogein. Data are means and $\mathrm{SD}, n=3$. (c) Total ROS levels produced during a $90 \mathrm{~min}$ period (same experimental design as that described in the legend of figure 4). Data are expressed as percent compared to the ROS level of BY-2 cells being set to 100 (corresponding to 500 nmoles $\mathrm{H}_{2} \mathrm{O}_{2}$ eq./g of cells). Means and SD for 3 independent experiments. Statistical differences for the total ROS level was assessed using a one-way ANOVA, with a Tukey honestly significant difference (HSD) multiple mean comparison post hoc test. Different letters indicate a significant difference, Tukey HSD, $\mathrm{P}<0.05$. (d) Cell density of untreated transgenic lines. 876 Packed cell volume (PCV) and dry weight (DW), were expressed in percent. Presented data 877 are means and SD for 6 independent experiments ( $n=6$ samples for each cell line). Control 878 (empty vector) and overexpressors were compared to WT BY-2 suspensions using a one-way 879 ANOVA, with a Tukey honestly significant difference (HSD) multiple mean comparison post $880 h o c$ test. For PCV, different letters indicate a significant difference, Tukey HSD, $\mathrm{P}<0.05$. No 
881 significant difference could be detected for DW (Tukey HSD, $\mathrm{P}<0.05$.) significant differences

882 (Tukey HSD, $\mathrm{P}<0.01$ ) in PCV and DW between genotypes were detected. Letters marked 883 with an apostrophe (') are used for DW data.

884 
Figure 6: Characterization of DGK Cluster III-targeted miRNA transgenic cell lines. (a) Scheme of the nucleic region targeted by the miRNA construct (see also Supporting information Fig. S2). (b) Evidence for miRNA production in planta. The cluster III-specific miRNA construct was expressed in tobacco leaves using Agrobacterium tumefaciens (GV3101). Foliar samples were harvested 2 day-post inoculation. Total RNAs were extracted, the cluster III pri-miRNA was specifically reverse transcribed using a stem-loop system and generated cDNA used as template for PCR amplification (expected size of PCR product $=181 \mathrm{bp}$ ). Sequencing showed PCR products to be the hairpin construct. (c) Expression levels of cluster III and NtDGK5-like genes in miRNA cell lines. Expression levels were quantified by Q-PCR on samples obtained from untreated 7-day-old cell suspensions. Means and SD are from 4 independent biological replicates ( $n=4$ samples for each cell line). The empty vector line corresponds to a line transformed with an empty pH7GWIWG2(II). (d) Cell suspension density of 7 day-old transgenic lines. Packed cell volume (PCV) and dry weight (DW), are expressed as a \%. Presented data are means and SD for 6 independent biological replicates ( $\mathrm{n}=6$ samples for each cell line). The empty vector line and the hp-clusterIII- $A$ and hp-clusterIII-B cell lines were compared to WT BY-2 suspensions using a one-way ANOVA, with a Tukey honestly significant difference (HSD) multiple mean comparison post hoc test. No significant differences (Tukey HSD, $\mathrm{P}<0.01$ ) in PCV and DW between genotypes were detected. Letters marked with an apostrophe (') are used for DW data. 

inhibits the oxidative burst in response to cryptogein. (a) Levels of PA in response to cryptogein. Cells were radiolabeled for $20 \mathrm{~min}$ before lipid extraction. Lipids were extracted 10 min after cryptogein addition. TLC plates were developed using an acid solvent system. 909 The radioactivity associated with PA was normalized to that of PE and PC. For each line, the 910 data are expressed as \% of the value of the non-elicited cells. For each treatment, 3 flasks of cells were used and the data are mean $\pm \mathrm{SD}, n=3$. Statistical difference between treated and non-treated conditions was assessed by a Student T-test, where * indicates $\mathrm{P}<0.05$. (b) Time913 course of ROS levels following elicitation with cryptogein. Data are means and SD for 8 914 independent biological replicates ( $\mathrm{n}=8$ samples per kinetic point for each cell line). (c) Total amounts of ROS produced over a 90 min period after cryptogein addition (same data as in panel b). Statistical differences was assessed using a one-way ANOVA, with a Tukey

917 honestly significant difference (HSD) multiple mean comparison post hoc test. Different 918 letters indicate a significant difference, Tukey HSD, $\mathrm{P}<0.01$. 
(a)

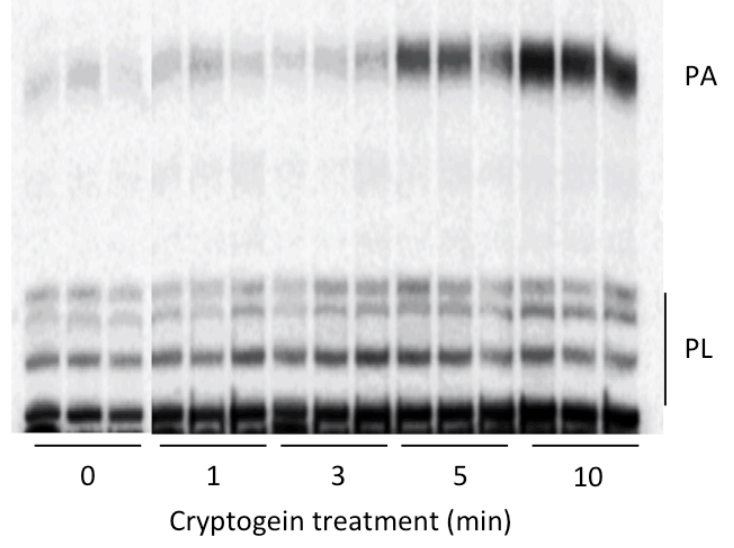

(b) Cryptogein treatment (min)

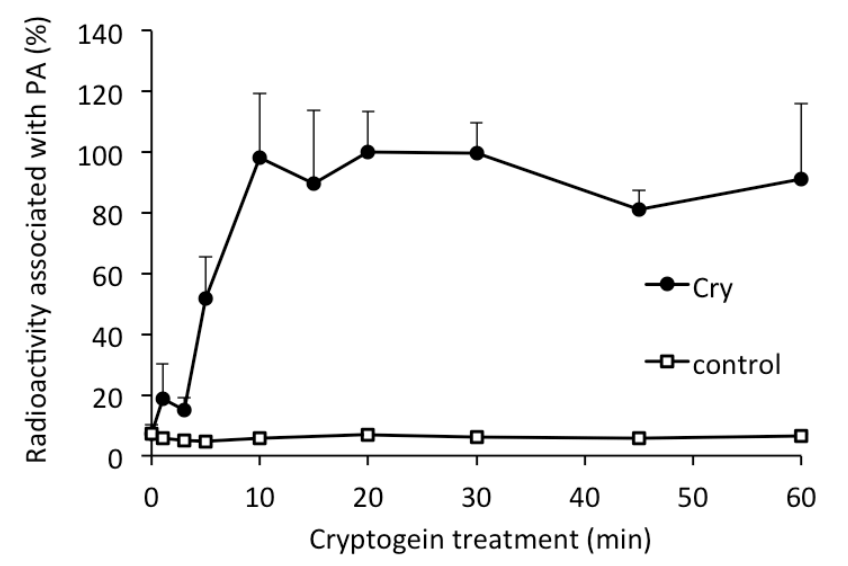

$921 \quad$ Figure 1 
(a)

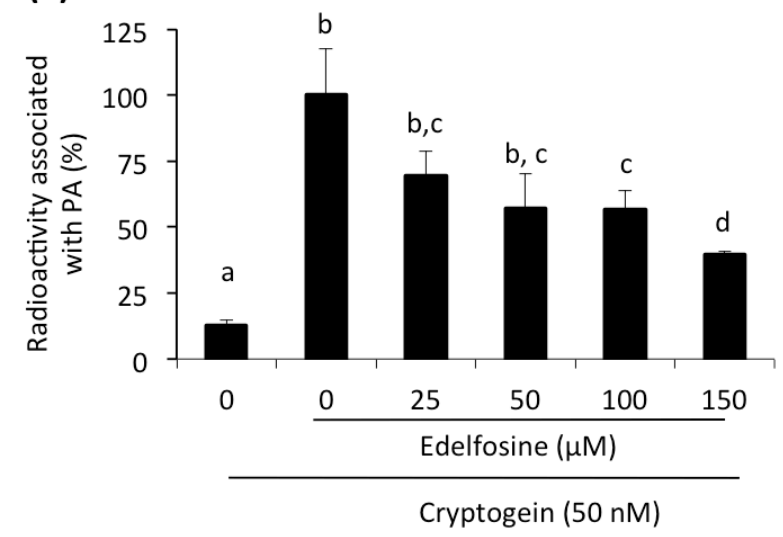

(c)

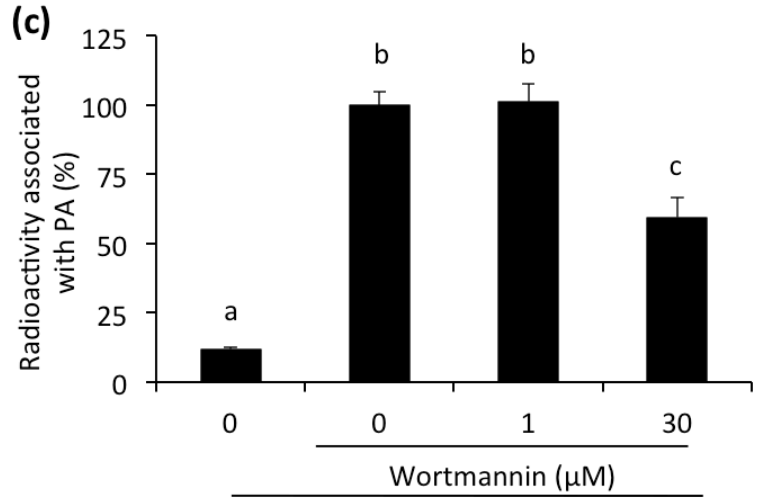

Figure 2 Cryptogein (50 nM) (b)
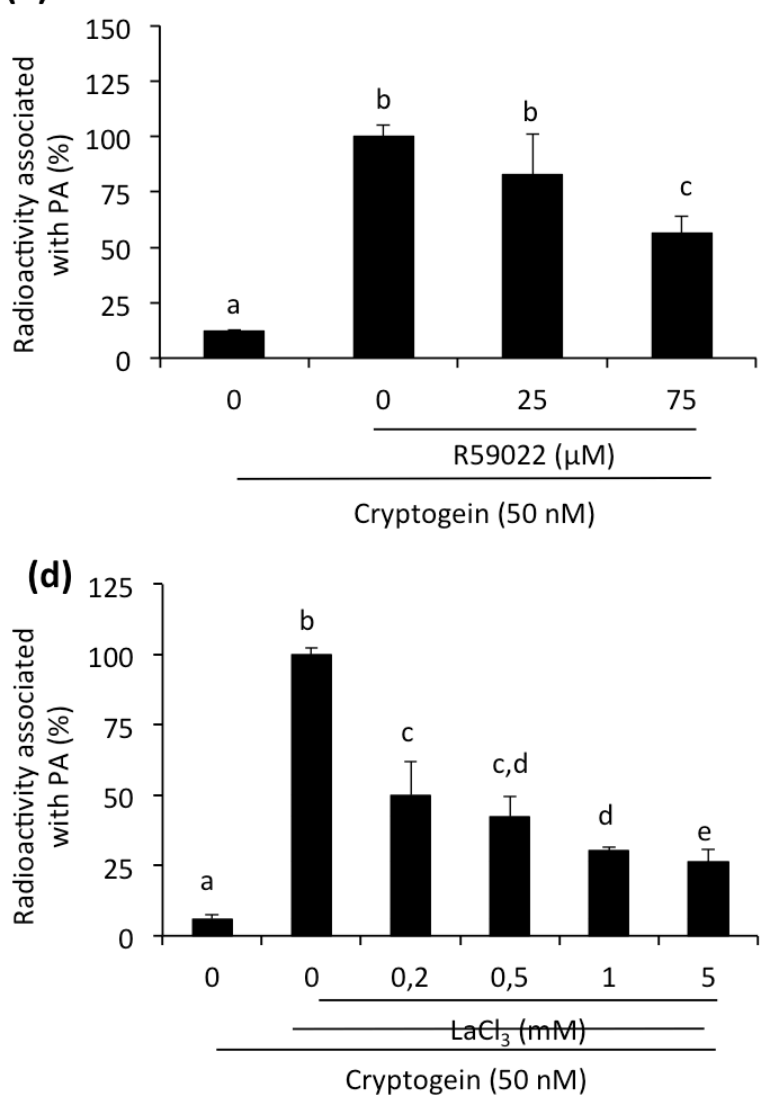
(a)

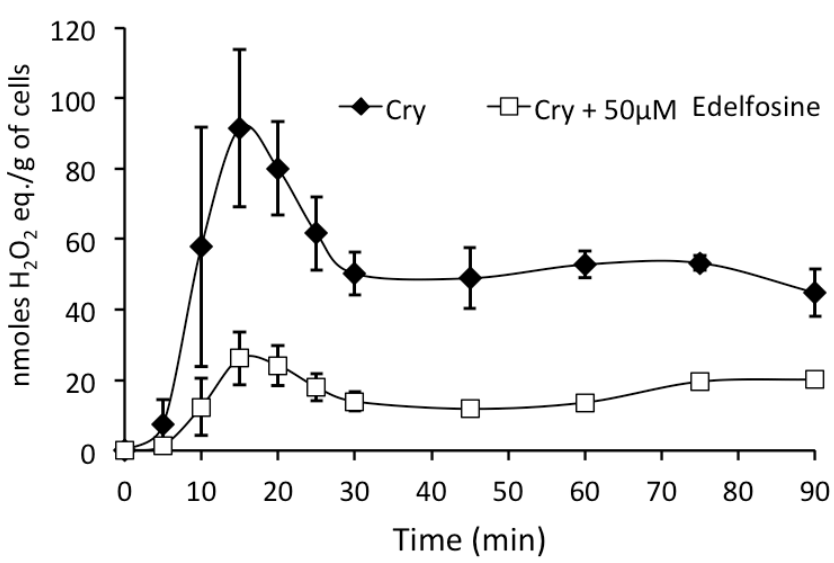

(c)

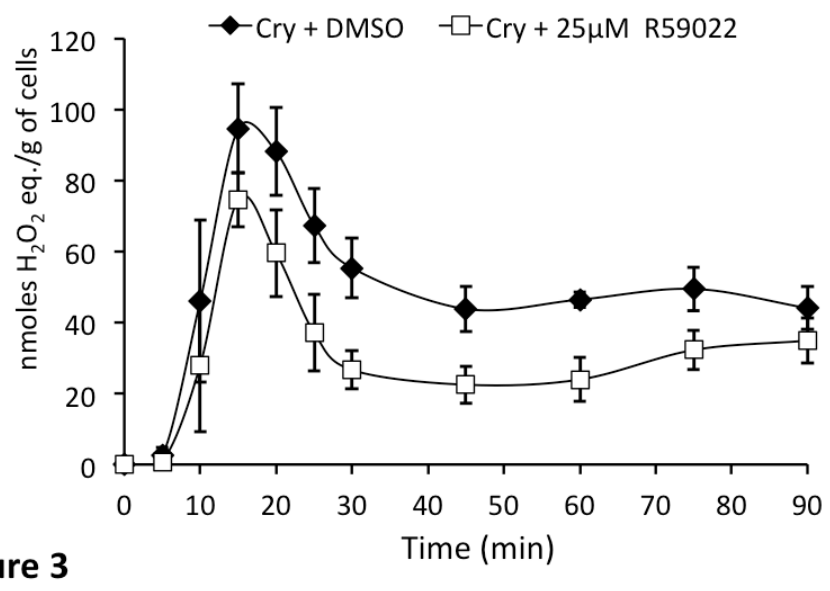

(b)

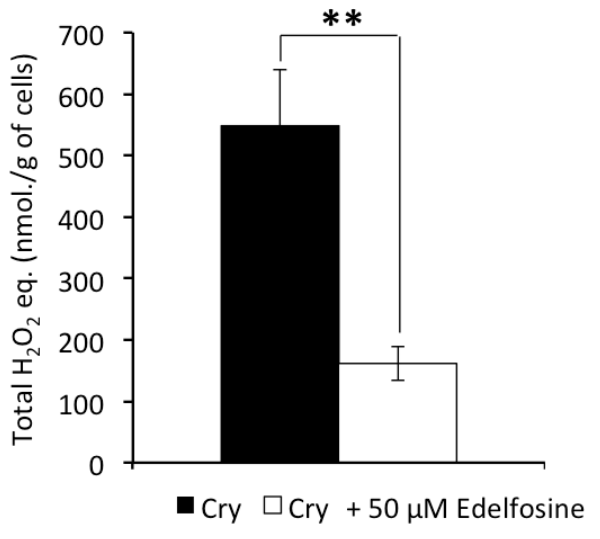

(d)

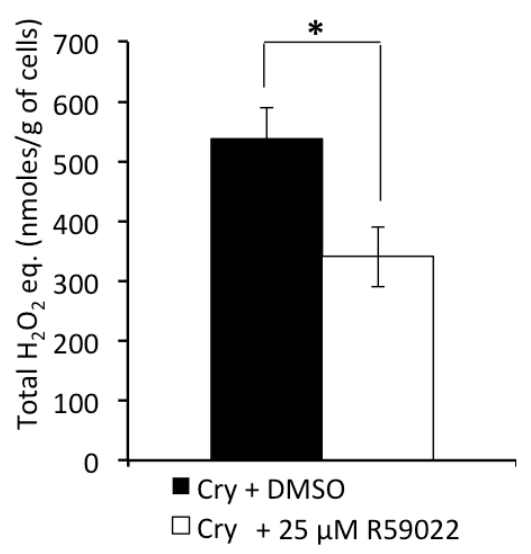




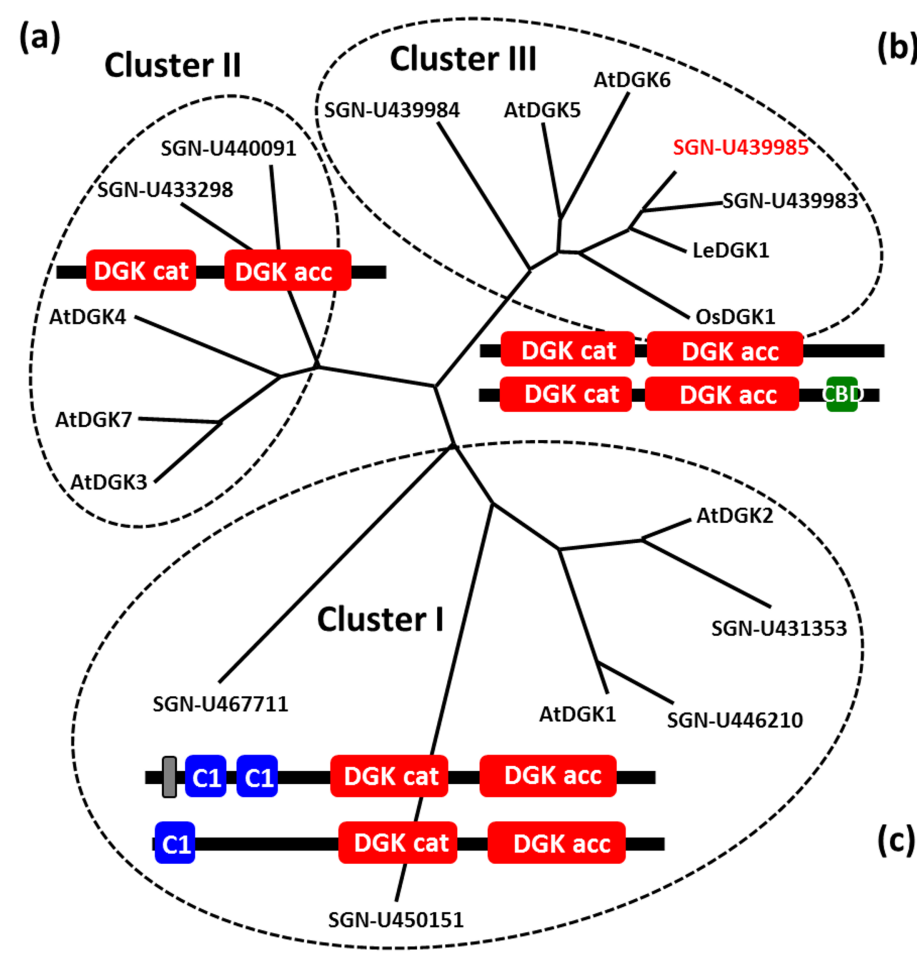

(b)

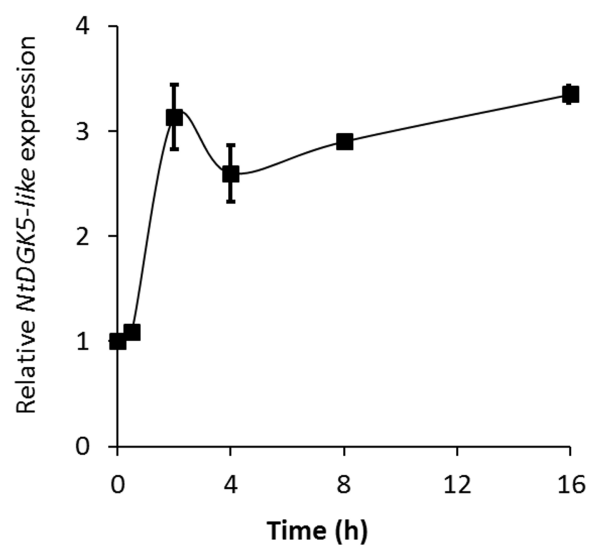

(c)

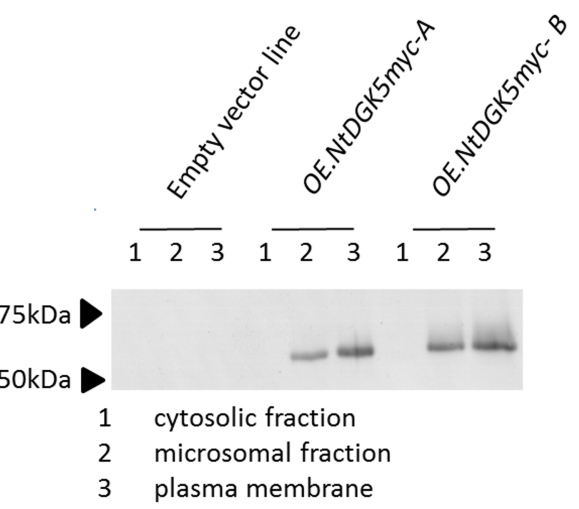


(a)

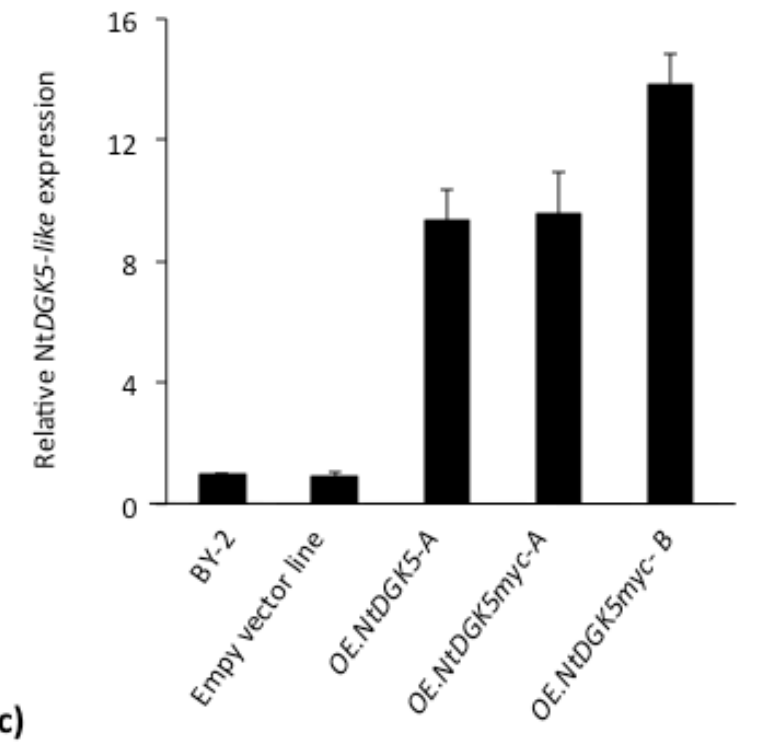

(b)
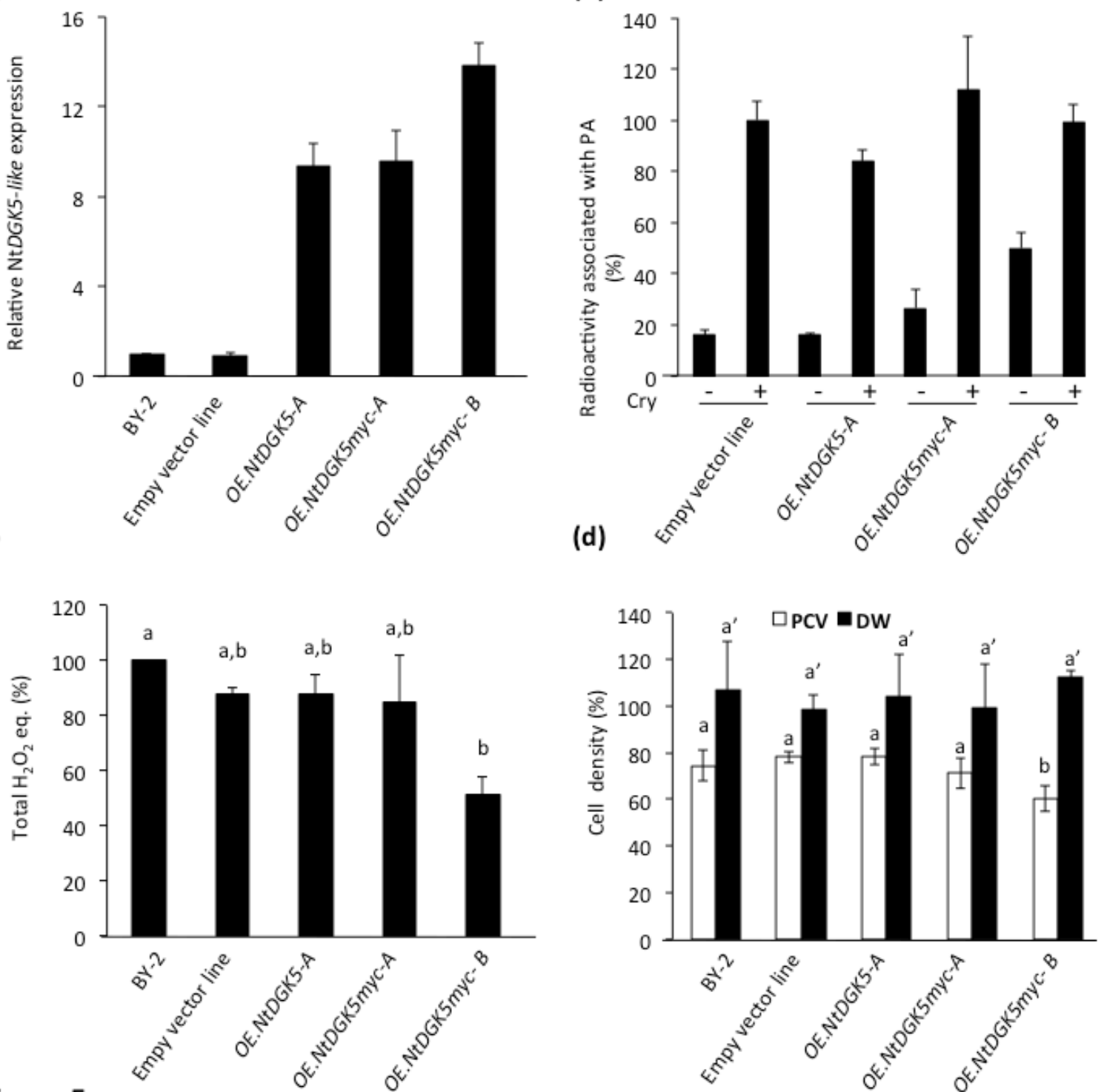

Figure 5

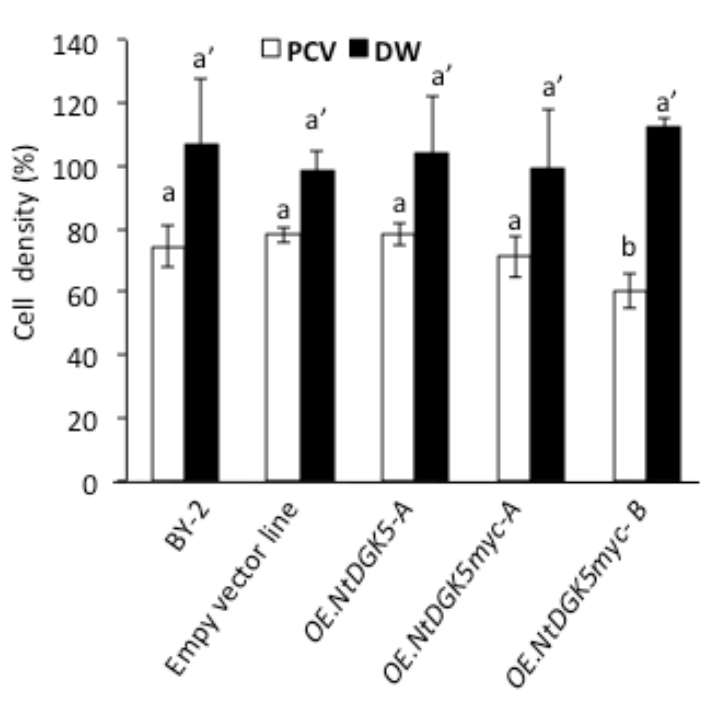


(a)

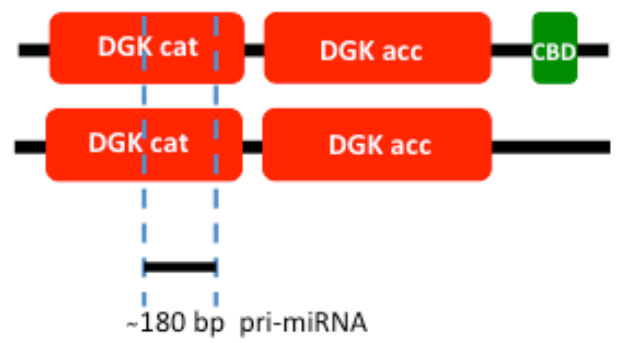

(c)

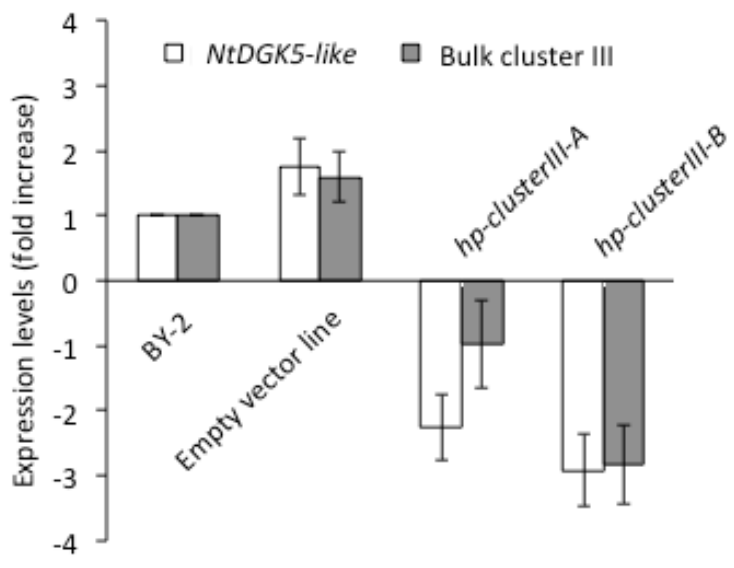

Figure 6 (b)

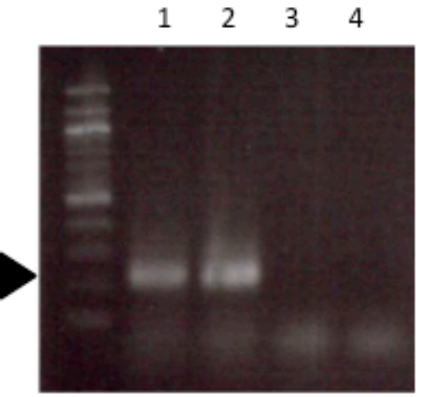

(d)

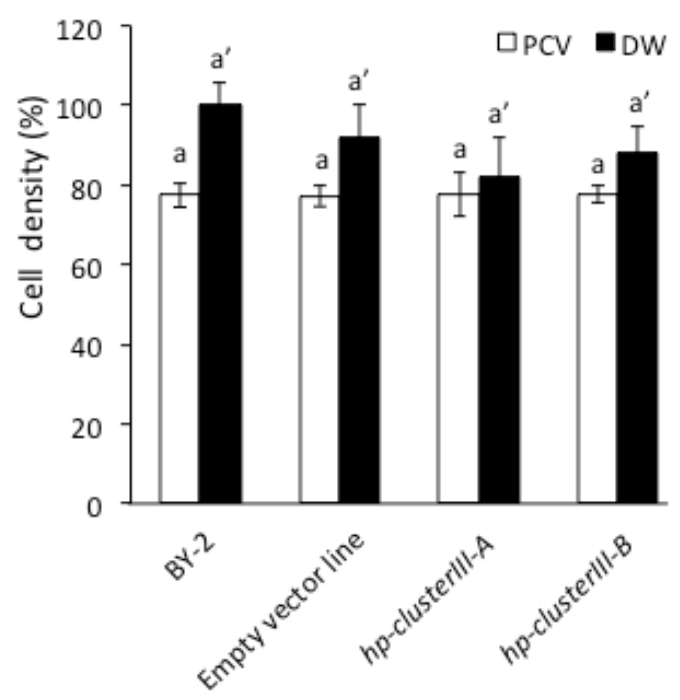

932 
(a)

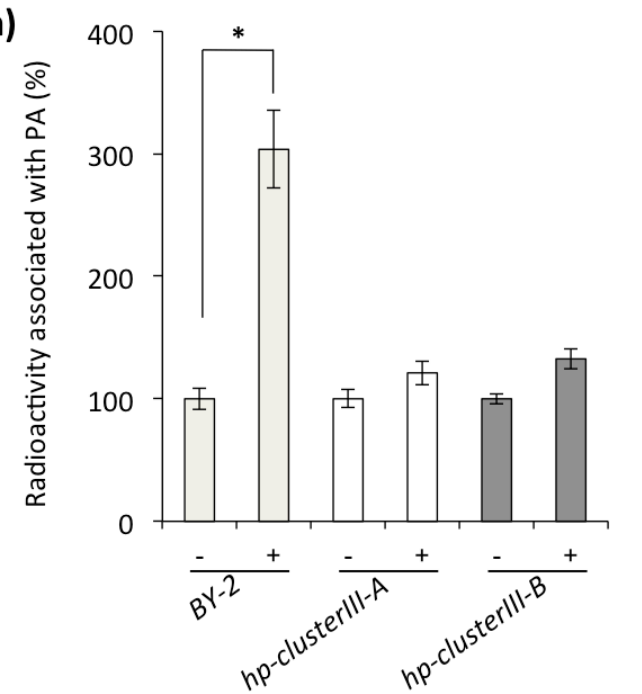

933

(c)

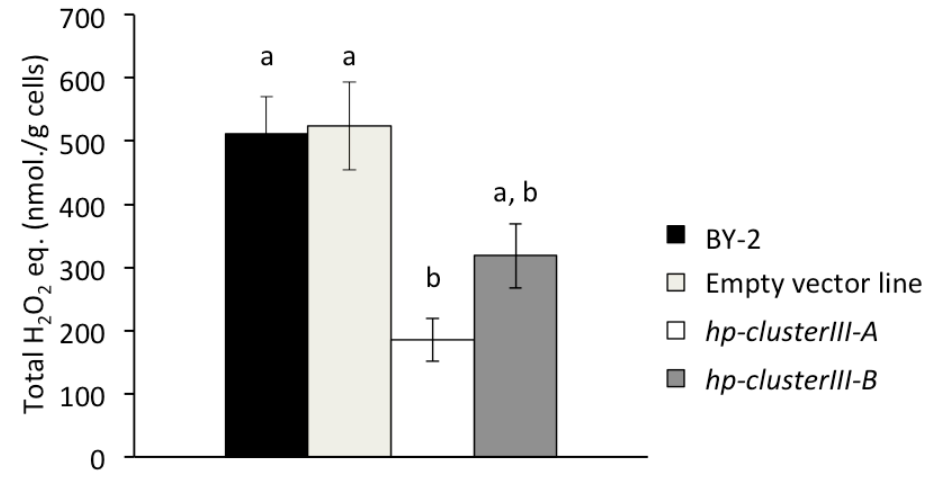

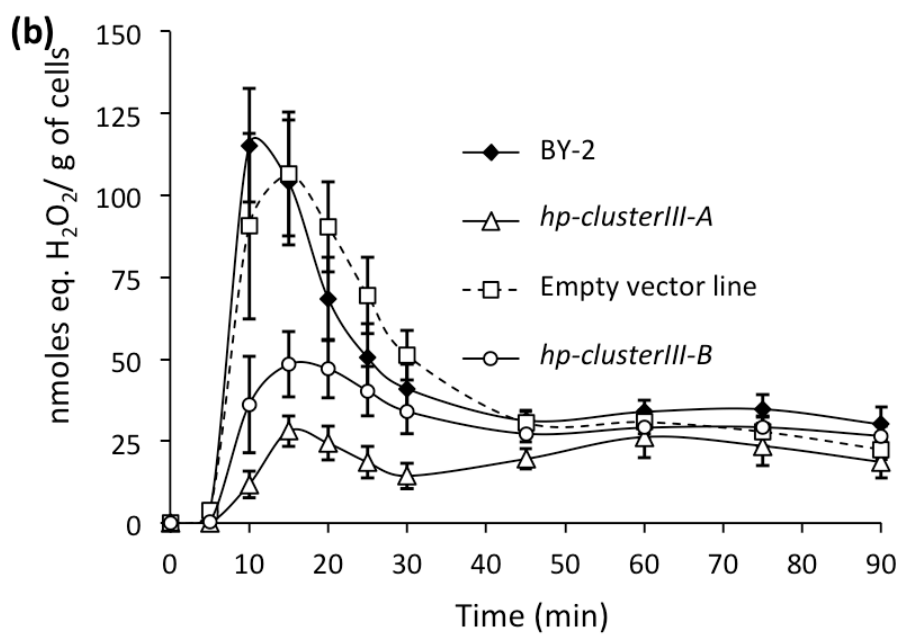

Figure 7 
Supporting information figure S1: The translated coding sequence of the tobacco NtDGK5-

like gene. The identified nucleic acid sequence was deposited in GenBank under the reference KU934207. It codes for a 493-amino acid-long protein $(55.24 \mathrm{kDa})$, having a predicted $\mathrm{pI}$ of 6.75. In silico translation was performed using the freeware ORF Finder available at the NCBI website (http://www.ncbi.nlm.nih.gov/gorf/gorf.html).

Supporting information figure S2: Partial alignment of plant DGK coding sequences from clusters II and III. This figure shows the nucleic acid coding region used for miRNA design (squared in red), which is highly conserved among cluster III members and divergent with cluster II counterparts. Full-length nucleic acid sequences were aligned using version 2.0.10 of Clustal X (Larkin et al. 2007) and the resulting alignment was processed online at the BoxShade server (http://www.ch.embnet.org/software/BOX_form.html). Roman numbers (II and III) on the right of the alignment indicate DGK cluster.

Supporting information figure S3: Effects of inhibitors on the alkalization triggered by cryptogein. Cells were preincubated 15 min with inhibitors (or DMSO, solvent of the inhibitors) before cryptogein $(50 \mathrm{nM})$ elicitation. Final concentrations of edelfosine, R59022 and R59949 were $25 \mu \mathrm{M}, 75 \mu \mathrm{M}$ and $75 \mu \mathrm{M}$, respectively. R59949 is another DGK inhibitor. Extracellular $\mathrm{pH}$ alkalinization was measured and reported as the difference between initial and final (1 hour of cryptogein treatment) $\mathrm{pH}$ values. Means +/- SD.

Supporting information figure S4: Topology of the sixteen identified tobacco DGK proteins. Protein structure is depicted for the 3 phylogenetic clusters. DGK nucleic acid sequences were retrieved from the Solanacea Genomics Network (SGN) database (https://solgenomics.net/) using the BLAST algorithm and keyword search tool. Known Arabidopsis, rice and tomato DGKs were used as nucleic acid sequence queries. Upon in 
959

silico translation using ORF Finder (http://www.ncbi.nlm.nih.gov/gorf/gorf.html), the resulting polypeptides were compared to their Arabidopsis counterparts and the Conserved Domain Architecture Retrieval Tool (CDART, (Geer et al. 2002)) was used to predict domain location. Within a panel (corresponding to one protein cluster), the closest Arabidopsis relative is followed by orthologous tobacco translated sequences. The latter are referenced by their SGN numbers and the identified part of the protein is presented. The length of the corresponding contigs is also indicated in green. Abbreviations: AtDGK5lv, AtDGK5 long splice variant; AtDGK5sv, AtDGK5 short splice variant; C1, DAG binding domain; CBD, calmodulin-binding domain; DGKcat, DGK catalytic domain; DGKacc, DGK accessory domain. The grey rectangle localized to the N-terminal part of AtDGK1 represents a transmembrane domain.

Supporting information figure S5: Identification of the PA binding domain of NtRBOHD by alignment with the cognate domain of Arabidopsis isoform D. Full length primary aminoacid sequences of RBOHD from Arabidopsis thaliana (SwissProt:Q9FIJ0.1) and Nicotiana tabacum (GenBank:ABN58915) were aligned using version 2.0.10 of Clustal X (Larkin et al. 2007) and the resulting alignment was then processed online at the BoxShade server (http://www.ch.embnet.org/software/BOX_form.html). Stars indicate the two basic aminoacid residues experimentally proven to be critical for interaction with PA (Zhang et al. 2009). Note the conservation of these residues between the two proteins. 